\title{
5-Fluorouracil-induced RNA stress engages a TRAIL-DISC- dependent apoptosis axis facilitated by p53
}

\author{
Birce Akpinar ${ }^{1}$, Ethiene V. Bracht ${ }^{1}$, Dorin Reijnders ${ }^{1}$, Barbora Safarikova ${ }^{2}$, \\ Iva Jelinkova ${ }^{2}$, Alf Grandien ${ }^{3}$, Alena Hyrslova Vaculova ${ }^{1,2}$, Boris Zhivotovsky ${ }^{1}$, \\ Magnus Olsson ${ }^{1}$ \\ ${ }^{1}$ Division of Toxicology, Institute of Environmental Medicine, Karolinska Institutet, Stockholm, Sweden \\ ${ }^{2}$ Department of Cytokinetics, Institute of Biophysics, Academy of Sciences of the Czech Republic, v.v.i., Brno, Czech Republic \\ ${ }^{3}$ Department of Medicine, Center for Infectious Medicine, Karolinska Institutet, Karolinska University Hospital-Huddinge, \\ Stockholm, Sweden
}

Correspondence to:

Boris Zhivotovsky, e-mail: Boris.Zhivotovsky@ki.se

Keywords: colon cancer, apoptosis, 5-fluorouracil, p53, necrosis

Received: July 22, $2015 \quad$ Accepted: October 12, $2015 \quad$ Published: October 24, 2015

\section{ABSTRACT}

Despite recent advances in targeted therapeutics, administration of 5-fluorouracil (5-FU) remains a common clinical strategy for post-surgical treatment of solid tumors. Although it has been proposed that RNA metabolism is disturbed by 5-FU treatment, the key cytotoxic response is believed to be enzymatic inhibition of thymidylate synthase resulting in nucleotide pool disproportions. An operating p53 tumor suppressor signaling network is in many cases essential for the efficiency of chemotherapy, and malfunctions within this system remain a clinical obstacle. Since the fate of chemotherapy-insensitive tumor cells is rarely described, we performed a comparative analysis of 5-FU toxicity in p53-deficient cells and conclude that p53 acts as a facilitator rather than a gatekeeper of cell death. Although p53 can act as a regulator of several cellular stress responses, no rerouting of cell death mode was observed in absence of the tumor suppressor. Thus, the final death outcome of 5-FU-treated p53 a slow pace, accumulation of mitochondrial reactive oxygen species contributes to necrotic characteristics. The oligomerization status of the p53 target gene DR5 is determined as a significant limiting factor for the initiation of caspase activity in an intracellular TRAIL-dependent manner. Using several experimental approaches, we further conclude that RNA- rather than DNA-related stress follows by caspase activation irrespectively of p53 status. A distinct 5-FU-induced stress mechanism is thereby functionally connected to a successive and discrete cell death signaling pathway. Finally, we provide evidence that silencing of PARP-1 function may be an approach to specifically target p53-deficient cells in 5-FU combinatorial treatment strategies. Together, our results disclose details of impaired cell death signaling engaged as a consequence of 5-FU chemotherapy. Obtained data will contribute to the comprehension of factors restraining 5-FU efficiency, and by excluding DNA as the main stress target in some cell types they propose alternatives to currently used and suggested synergistic treatment regimens.

\section{INTRODUCTION}

Administration of 5-fluorouracil (5-FU, fluorouracil) is a common post-surgical treatment regimen used for several categories of solid tumors, and especially for patients suffering from colorectal cancers (CRC). The therapeutic potential of 5-FU was primarily described as an effect of its metabolic conversion into fluorodeoxyuridine monophosphate (FdUMP), a suicide substrate for thymidylate synthase (TS), and as such able to starve 
cells from deoxythymidine monophosphate (dTMP) [1]. By this means, a rate-limiting step obligatory for DNA replication and repair is eliminated and a link to cell death mechanisms provided. Fluorouridine triphosphate (FUTP), on the other hand, can be misincorporated into RNA. In fact, drug activity patterns derived from gene expression profiles in 60 human cancer cell lines clustered 5-FU to RNA synthesis inhibitors [2]. Misincorporation of 5-FU metabolites into RNA transcripts and genomic DNA appears to occur simultaneously in tumor cells, but no significant correlation between the magnitude of integration into either species and the response to 5 -FU therapy has yet been found [3]. Hence, despite the extensive clinical use of 5-FU, the relative importance of each stress target is not clearly established.

Similar to other chemotherapeutic agents, 5-FU induces cell cycle arrest and apoptosis in sensitive tumor cell lines. While an arrest in the G1/S cell cycle phase boundary was reported to occur as a result of checkpoint kinase 1 (Chk1)-mediated Cdc25A inactivation [4], the mechanisms leading to the commencement of apoptosis signaling are poorly understood. Since the p53 tumor suppressor plays a central role in DNA damage responses, including DNA repair, the cell cycle regulations and apoptosis, a key focus has been on how these processes relate to 5-FU toxicity. For instance, gene expression analyses identified mitochondrial ferredoxin reductase as a p53 target gene inducing cell death via mitochondrial reactive oxygen species (ROS) formation [5]. In vivo and in vitro studies also suggest that 5-FU-treated cancer cells conform to a p53-dependent extrinsic apoptosis mechanism directed by receptors included in the tumor necrosis factor family (TNF) [6, 7]. Yet, although p53 status was proposed as an accurate indicator of CRC prognosis and 5-FU therapy response in vivo and in vitro [8-10], it is still a matter of debate. For example, a correlation between mutations in the conserved p53 DNA binding region and treatment efficacy indicated that this aspect of protein function is not a clinically useful predictive marker for the response of Dukes' C stage colon cancers to 5-FU chemotherapy [11]. Nevertheless, in experimental models where p53 status has been used to explain gross differences in 5-FU responses, it is evidently clear that cells harboring p53-insufficiency are also affected by treatment [9, 12]. In contrast to the analysis of functional stress pathways where the silencing of key regulatory elements mostly serves as controls, we have explored in detail the kinetics and underlying mechanisms of p53-independent cell death by using parental and genetically-modified HCT116 cells, one of the most common in vitro systems for 5-FU toxicity analyses. By this experimental approach, we clarified the role of the tumor suppressor in several aspects of drug toxicity, ranging from initial stress target point to molecular mechanisms of apoptosis and cell fate. We also provide evidences supporting a mechanism by which tumor cells lacking p53 are sensitized to 5-FU combinatorial treatment strategies targeting PARP-1.

\section{RESULTS}

\section{p53 facilitates the appearance of apoptotic markers in 5-FU-treated HCT116 cells}

HCT116 has been verified as type II cells [13], stating that mitochondrial destabilization is required for efficient apoptosis. The HCT116 parental $(w t)$ cell line and its derivate lacking p53 (HCT116 p53 $3^{--}$) were, therefore, treated with 5-FU and analyzed with respect to loss of mitochondrial membrane potential (MMP, $\Delta \Psi_{\mathrm{m}}$ ), release of cytochrome $c$ into the cytosol, DEVDase (caspase-3/-7like) activity and poly(ADP-ribose) polymerase-1 (PARP-1) cleavage. Notably, although all markers appeared earlier and were more pronounced in $w t$ cells, they could also be readily detected independently of p53 function (Figure 1A-1D). Interestingly, although the DEVDase activity in HCT116 $p 53^{-/-}$cells at $48 \mathrm{~h}$ of treatment only reached approximately half the intensity compared to their $w t$ counterpart at $24 \mathrm{~h}$ (Figure 1B), similar rates of overall cell death were quantified by FACS analysis of the subG1-population in both data sets (Figure 1E). Thus, the consequence of p53 deficiency in this context is indeed a suboptimal apoptotic signaling cascade which, however, generates substantial cell death in a timely delayed manner. Apart from experimental conditions where efficient cell death was assured by using high doses of 5-FU $(768 \mu \mathrm{M})$, treatment for $48 \mathrm{~h}$ using lower concentrations of the drug $(10 \mu \mathrm{M})$ also generated substantial apoptosis, both in the absence or presence of p53 (Figure 1E). Similar colony formation capacity in both cell types over a range of 5-FU concentrations was observed (Figure 1F). However, the presence of a pan-caspase inhibitor (zVAD-fmk) does not rescue tumor cell colony formation in p53-deficient cells (Supplementary figure 1A). This indicates that during culture conditions where cells are seeded sparse $\left(<20\right.$ cells $\left./ \mathrm{cm}^{2}\right) 5$-FU treatment does not engage cell death pathways, as is the case in "normal culture settings" $\left(5 \times 10^{4}\right.$ cells $\left./ \mathrm{cm}^{2}\right)$, but primarily follows by a $\mathrm{p} 53$ independent cell cycle arrest. In support of this observation, cells were arrested in a G1/S cell cycle boundary within 8 hours of treatment irrespectively of p53 (Supplementary figure 1B).

\section{Despite necrotic characteristics 5-FU-treated HCT116 $\mathrm{53}^{-/-}$cells primarily die by caspase- dependent apoptosis}

Previously, we identified a novel signaling route occurring as a consequence of 5-FU-induced entry of extracellular $\mathrm{Ca}^{2+}$, where calmodulin served as a link to p53 phospho-activation and apoptosis [6]. $\mathrm{Ca}^{2+}$-overload 
may also induce programmed necrosis resulting from a calpain-dependent mitochondria-nuclei translocation of the apoptosis-inducing factor (AIF) [14]. We, therefore, speculated that in p53-deficient HCT116 cells where apoptosis is suboptimal, alternative cell death modes may become more pronounced. Indeed, 5-FU-treated HCT116 $p 53^{--}$cells display several molecular and biochemical characteristics of necrosis, including plasma membrane disintegration, determined by extracellular lactate dehydrogenase (LDH) and transmission electron microscopy (TEM) (Figure $2 \mathrm{~A}$ and $2 \mathrm{~B}$ ). These features were in sharp contrast to treated HCT116 wt cells where plasma membranes remained intact in apoptotic cells (Figure 2A and 2B).
Importantly, in absence of p53 cellular release of LDH was completely abrogated by the pan-caspase inhibitor zVAD-fmk, suggesting that the predominant cell death mode is indeed caspase-dependent (Figure 2C). To clarify how necrotic signatures evolve in apoptotic HCT116 $p 53^{-/}$cells, 5-FU combinatorial treatments using chemical inhibitors to potential necrotic conduits, including the $\mathrm{Ca}^{2+}$ chelator BAPTA (1,2-bis (o-aminophenoxy)ethane-N,N,N',N'-tetraacetic acid), the RIP1-kinase inhibitor necrostatin 1 (NEC1), the antioxidant Trolox, and the inhibitor of lysosomal acid proteases pepstatin A were performed. As Trolox was the only compound able to limit LDH release, we concluded that ROS is a mediator of necrotic characteristics in
A

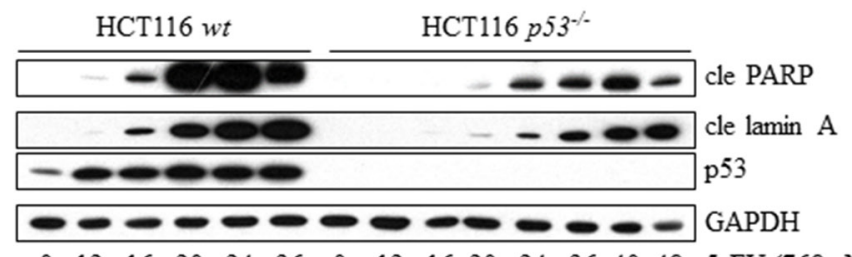

$\begin{array}{lllllllllllllll}0 & 12 & 16 & 20 & 24 & 36 & 0 & 12 & 16 & 20 & 24 & 36 & 40 & 48 & \text { 5-FU }(768 \mu \mathrm{M}, \mathrm{h})\end{array}$

B

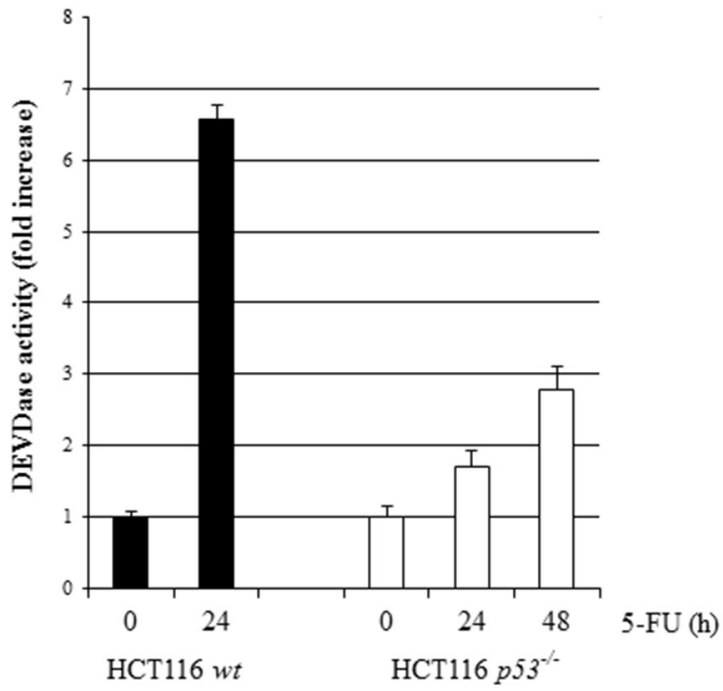

$\mathrm{C}$

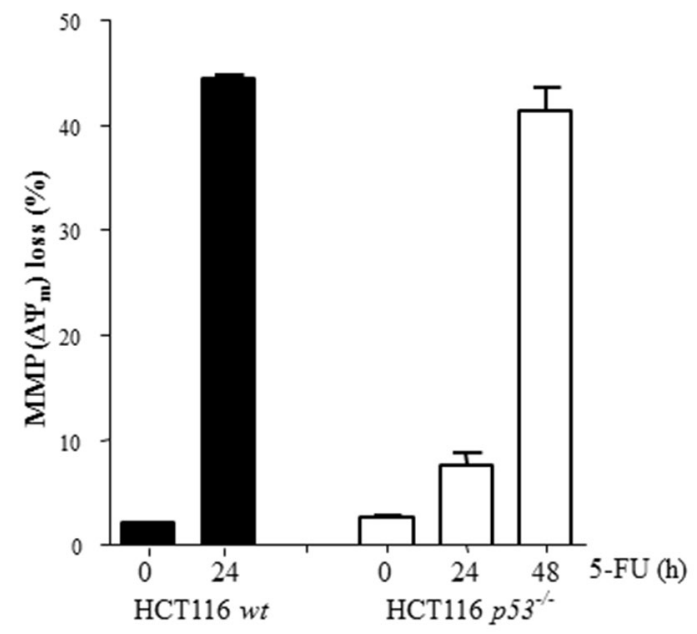

$\mathrm{D}$

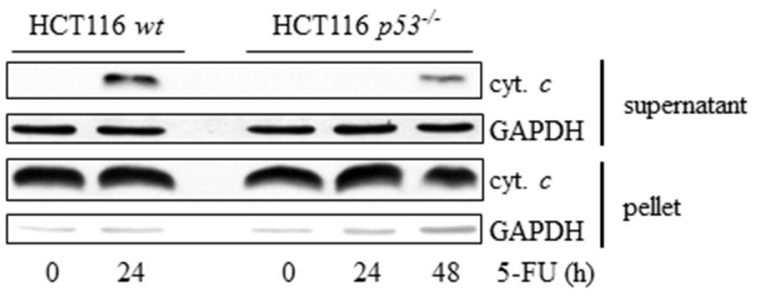

Figure 1: Comparative analysis of 5-FU-induced apoptosis in wt and p53-deficient HCT116 cells. The apoptotic indicators, cleaved PARP and lamin A (cle PARP, cle lamin A), were analyzed at multiple time points ranging from 0 to $36 \mathrm{~h}$ posttreatment initiation in $p 53$-proficient and 0 to $48 \mathrm{~h}$ in $p 53$-deficient HCT116 cells using immunoblotting of SDS-PAGE-separated cell lysates A. Caspase-3/-7-like activities were measured by monitoring the liberation of AMC from the synthetic fluoro-conjugated peptide substrate motif DEVD (DEVD-AMC) B. Drug effects with respect to loss of mitochondrial membrane potential $\left(\Delta \Psi_{\mathrm{m}}\right)$ in live cells were examined by FACS analysis of mitochondrial TMRE accumulation C. HCT116 wt and $p 53^{-\%}$ cells, treated with $768 \mu \mathrm{M} 5$-FU for time periods indicated, were harvested and subjected to separation into cytoplasmic and nuclear/mitochondrial fractions, enabling immunoblotting of released cytochrome $c \mathbf{D}$.

(Continued) 

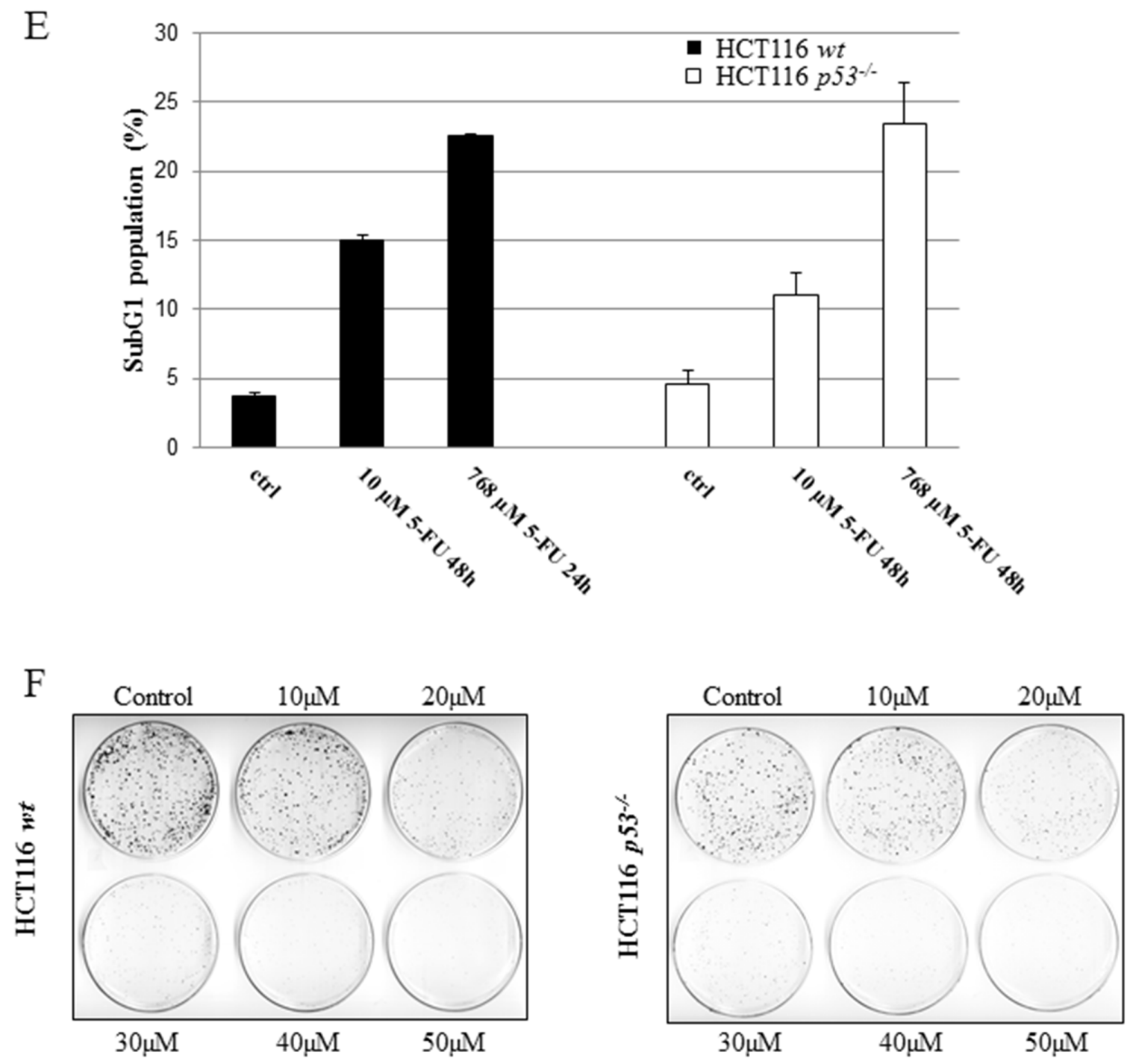

Figure 1: (Continued) Cells, treated with 5-FU (10 $\mu \mathrm{M}, 48 \mathrm{~h}$ or $768 \mu \mathrm{M}, 24 \mathrm{~h})$, were fixed in $70 \%$ ethanol and stained with propidium iodide before FACS determination of sub G1 populations E. Clonal survival of eighteen HCT116 wt or p53 $3^{-/-}$cells $/ \mathrm{cm}^{2}$ in response to 5-FU treatment (48 h), ranging from 10 to $50 \mu \mathrm{M} \mathrm{F}$. GAPDH served as a marker for equal sample loading in (A) and (D), and also as an indicator of fractionation efficacy in (D).

5-FU-treated cells harboring a disintegrated apoptotic program (Figure 2D). It is important to note that zVADfmk in the absence of p53 by no means obstructs the generation of mitochondrial ROS, nor does Trolox inhibit 5-FU-induced apoptosis, as determined by FACS analysis of MitoSOX ${ }^{\mathrm{TM}}$ Red-stained cells and SDSPAGE, respectively (Figure 2E and 2F). Mitochondrial release of AIF could not be detected in organelle fractions isolated from treated cells, thus excluding this as being an important factor for the necrotic features described (Supplementary figure 2). Moreover, necrotic morphology determined by TEM and LDH-release appears simultaneously as the initiation of cell death and the activation of caspases-8 and -3 (Figure 2A, Supplementary figure 3 ). In the presence of $\mathrm{p} 53$, an efficient apoptotic program does not allow ROS formation (Figure 2E). The distinct necrotic features of treated HCT116 $p 53^{--}$cells, on the other hand, may be an indirect consequence of suboptimal apoptosis and mediated by mitochondrial ROS, elevated in cells by mechanisms uncoupled from the apoptotic program.

\section{DR5-DISC determines apoptosis efficiency in a p53- and TRAIL-dependent manner}

Chemotherapeutic agents, such as platinum compounds and doxorubicin, have been reported to upregulate the TNF family death receptors DR4 and DR5 due to p53 transcriptional activity. As a result, chemotherapy in combination with TRAIL frequently 
augments cell death rates of cancer cells $[15,16]$. Since apoptosis in response to 5-FU was previously shown to depend on the TNF-family receptors in vivo and in vitro, as well as in the absence of TRAIL co-treatment, we examined whether or not p53 is critical for DISCmediated cell death. In support of this assumption a prominent apical caspase- 8 processing was detected in HCT116 p53 $^{-/}$cells (Supplementary figure 4A). Using a RNAi approach, we were also able to conclude that caspase- 8 is an upstream and essential factor for effector caspase activation in these cells (Supplementary figure 4B). To verify that caspase-8-activation occurs at the level of DISC formation, we investigated apoptotic markers appearing in response to 5-FU in HCT116 $p 53^{--}$cells stably overexpressing either the regulatory cellular caspase-8 (FLICE)-like inhibitory protein $\left(\mathrm{c}-\mathrm{FLIP}_{\mathrm{L}}\right.$ ) or a truncated version (dominant negative) of the Fas-associated death domain (FADD) adaptor protein (FADD-DN). Since both of these factors harbor a capacity to obstruct correct DISC formation, reduced levels of processed caspases and free cytosolic cytochrome $c$ in the case of ectopic c-FLIP ${ }_{\mathrm{L}}$ expression, and a decrease in active caspase- 3 in the case of FADD$\mathrm{DN}$ overexpression, justify our conclusion that 5-FU also induces DISC-mediated cell death in the absence of p53 (Figure 3A-3D). Previously, we revealed that DR5,
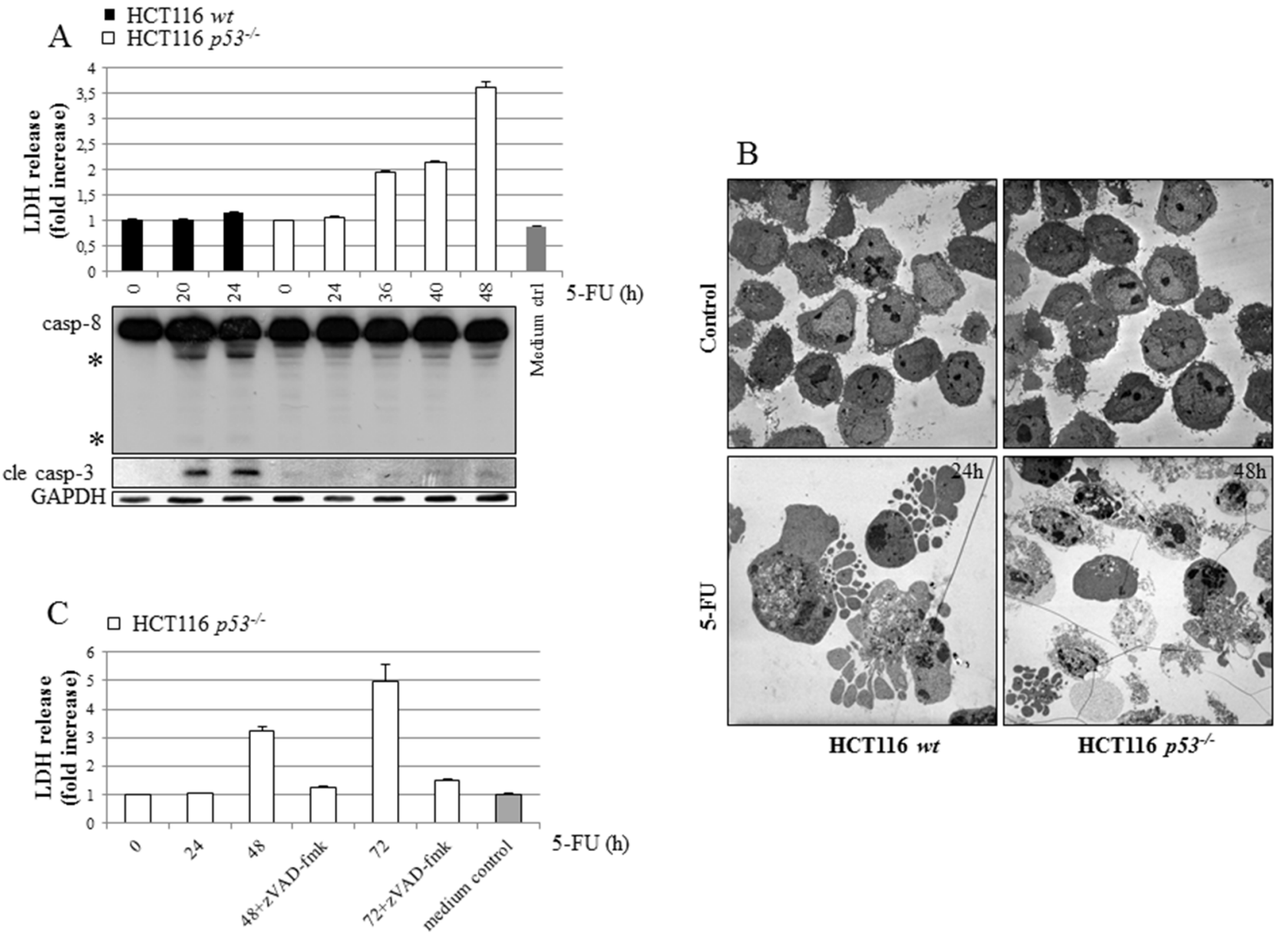

Figure 2: Irrespectively of p53 status, HCT116 cells die by apoptosis but characteristics of necrosis develop in the absence of the tumor suppressor as a consequence of ROS formation. HCT116 cells with different p53 status were treated with 5-FU $(768 \mu \mathrm{M})$, and at time points indicated cellular LDH release and SDS-PAGE-mediated detection of active subunits relating to caspases-3 (cle casp-3) and -8 were performed in parallel A. Representative transmission electron microscope images of sections prepared from control and 5-FU-treated $w t$ and $p 53^{-/}$cells. An isolation of dead cells was performed in treated samples by collecting floating cells prior to fixation and section preparation B. Analysis of LDH-release from HCT116 p53 ${ }^{-/}$cells at 24,48 and $72 \mathrm{~h}$ post-5-FU treatment $(768 \mu \mathrm{M})$, either in the presence or absence of the pan-caspase inhibitor zVAD-fmk $(10 \mu \mathrm{M})$ C. In D. HCT116 p53 ${ }^{-/}$cells were treated with 5 -FU for $48 \mathrm{~h}$, either alone or in the presence of chemical inhibitors of necrosis, inactive NEC (iNEC, $100 \mu \mathrm{M}), \mathrm{NEC}(100 \mu \mathrm{M}), \mathrm{BAPTA}$ $(10 \mu \mathrm{M}$, last $24 \mathrm{~h}$ only), Trolox $(50 \mu \mathrm{M})$ or pepstatin $\mathrm{A}(7 \mu \mathrm{M})$, in advance of LDH-release analysis. Mitochondrial ROS was measured by FACS analysis of control and 5-FU-treated MitoSOX ${ }^{\mathrm{TM}}$ Red stained HCT116 wt $(24 \mathrm{~h})$ and $p 53^{-/}(48 \mathrm{~h})$ cells, cultured either in the presence or absence of zVAD-fmk $\mathbf{E}$.

(Continued) 

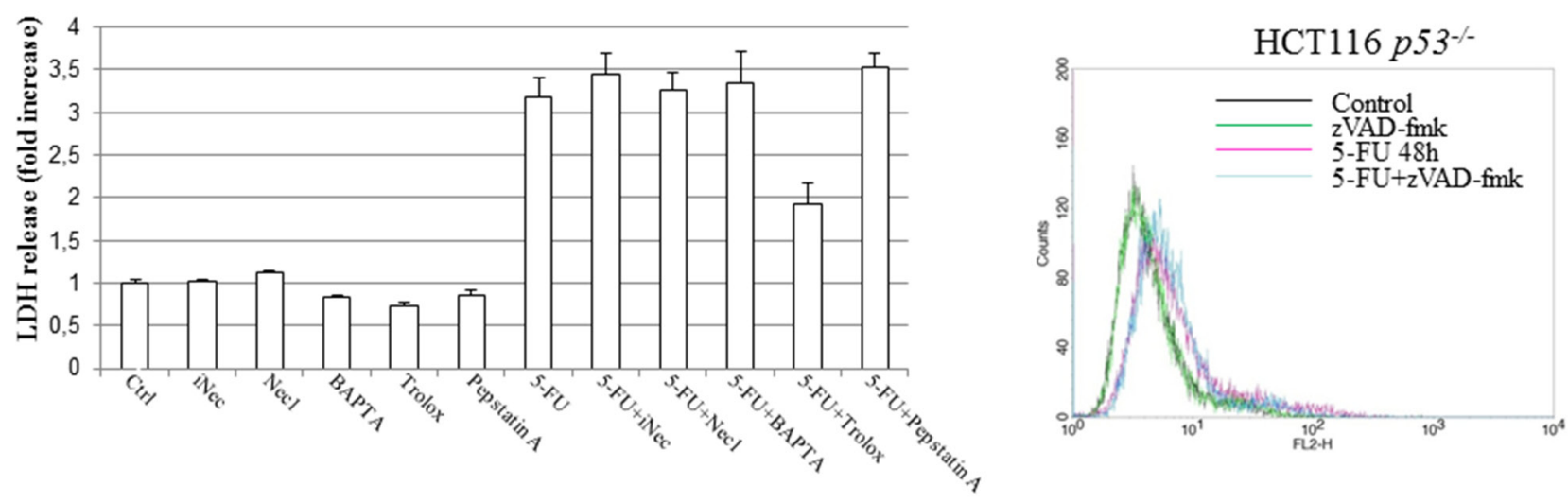

$\mathrm{F}$
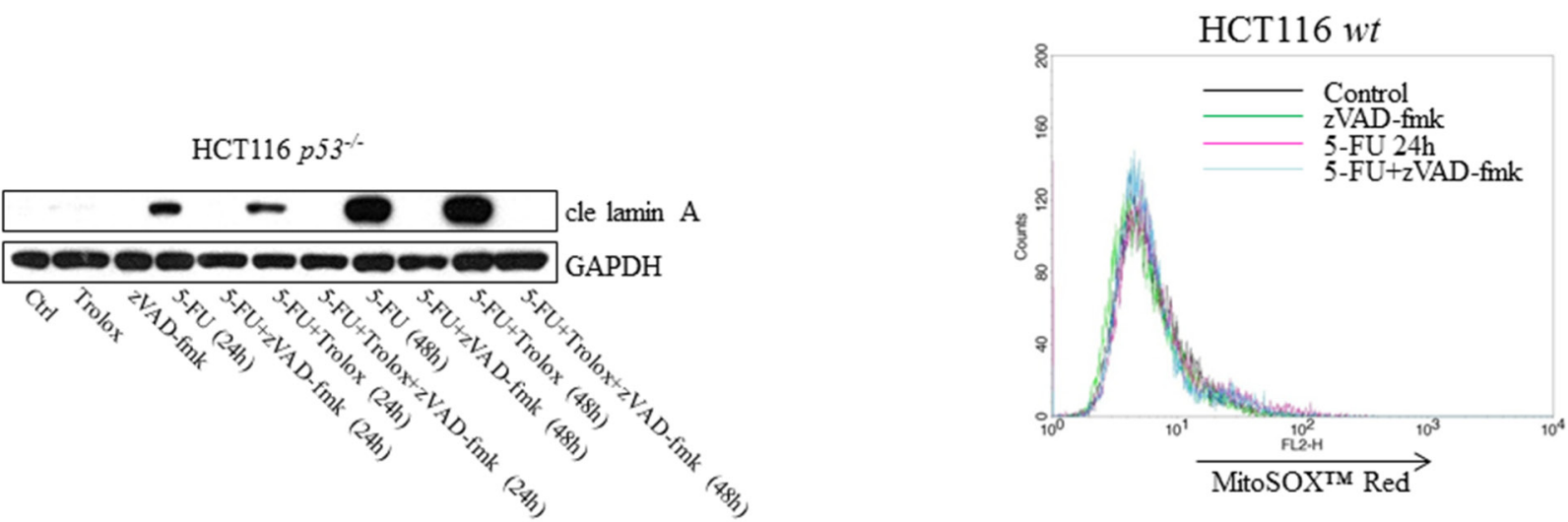

Figure 2: (Continued) Lysates isolated from cells treated with 5-FU, either alone or in combination with $50 \mu \mathrm{M}$ Trolox, were subjected to SDS-PAGE in order to investigate whether or not ROS reinforces apoptosis. Detection of cle lamin A served as an marker for apoptosis F. GAPDH probing indicates equal sample loading in $(\mathrm{A})$ and $(\mathrm{F})$. In $(\mathrm{A})$, processed caspase- 8 fragments are indicated with asterisks.

but not the Fas receptor, is fundamental for effective apoptosis in HCT116 wt cells [6]. Similar to their wt counterpart, 5-FU-induced apoptosis was abrogated by RNAi-silencing of DR5 also in HCT116 cells lacking p53, concluding that the absence of the tumor suppressor does not force cells to alter the death signaling pathway (Figure 4A). By using RNAi methodology, we also concluded DR4 as important for 5-FU-induced apoptosis, irrespectively of p53 function (Supplementary figure 5). Consistent with current data identifying DR4 and DR5 as p53 transcriptional target genes [17, 18], enhanced mRNA levels and accumulation of the corresponding proteins were more prominent in HCT116 $w t$ cells after $24 \mathrm{~h} 5$-FU treatment (Figure 4B and 4C, Supplementary figure 5). Interestingly, immunoblotting of cell lysates and immunoprecipitations (IP) using DR-specific antibodies also indicated a minor increase of the receptors independently of $\mathrm{p} 53$. These data were supported by an equivalent enhancement of the DR4 and DR5 mRNA's and also by the localization of the DR5 to plasma membranes in treated cells (Figure 4B-4D). Thus, DR4 and DR5 expression may be adjusted by both p53-dependent and -independent mechanisms where the latter may be a consequence of ER stress (Supplementary figure 6) [19]. To verify that DR5 is indeed oligomerized in response to treatment, protein lysates were isolated under non-reducing conditions and DR5 dimer formation analyzed by SDS-PAGE (Figure 4E). Since the presence of p53 supported dimer establishment, DR5 activity is established as one of the most upstream limiting apoptotic factor in the cell system analyzed. However, although the importance of DR4 and DR5 for 5-FUinduced apoptosis is clearly emphasized by these results, process(es) separated from the upregulations of DR4 and DR5 per se may contribute to activation of the receptors. In the current literature, TRAIL is postulated as the sole DR4/5-activating ligand. Apart from membrane-bound TRAIL, specific antibodies used in the study also detected a $\sim 24 \mathrm{kDa}$ protein fragment in high exposed immunoblotting, which is similar to the reported molecular weight of soluble TRAIL [20]. As this particular protein fragment appeared only in samples isolated from 5-FU-treated cells, we reasoned that there might be a connection to DR4/5 stimulation. 
A

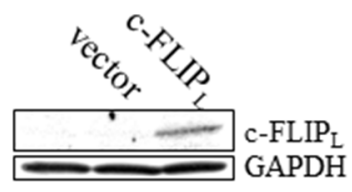

$\mathrm{D}$

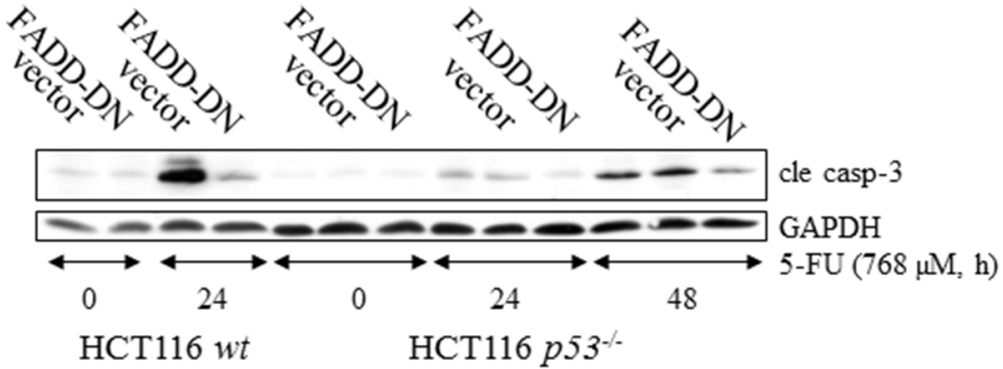

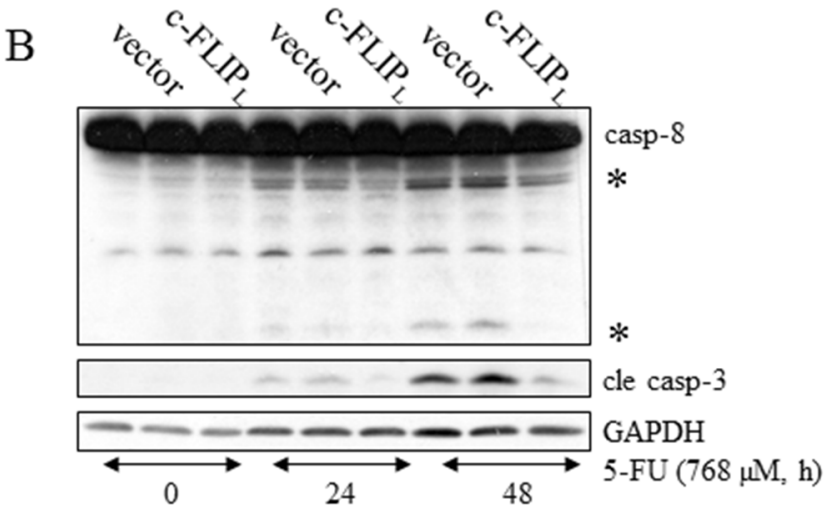

C

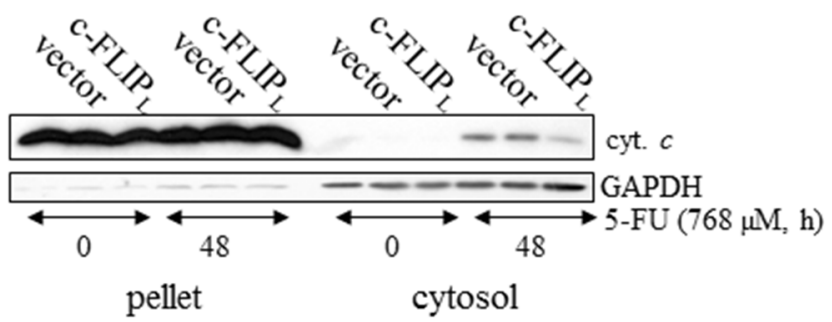

Figure 3: DISC activation is a prerequisite for caspase-dependent apoptotic signaling in p53-deficient HCT116 cells. $\mathrm{c}^{-F_{L} P_{\mathrm{L}}}$, FADD-DN or empty expression vectors were stably introduced into $w t$ and $p 53^{-/}$HCT116 cells by retroviral transduction. SDSPAGE- analysis of c-FLIP ${ }_{L}$ in lysates harvested from untreated HCT116 $p 53^{-/}$cells, transduced with empty or c-FLIP ${ }_{L}$ expression vectors A. Non-transduced, empty vector-containing and c-FLIP ${ }_{\text {L }}$ expressing HCT116 $p 53^{-/}$cells were harvested at the indicated time after 5-FU treatment and immunoblotting served to detect the processing of apical caspase- 8 and effector caspase-3 in B. Alternatively, cells were subjected to fractionation into cytoplasmic and mitochondrial/nuclei protein pools for analysis of cytochrome $c$ release $\mathbf{C}$. Control, empty vector-containing and FADD-DN expressing HCT116 $p 53^{-/-}$cells and HCT116 wt cells harboring empty and FADD-DN expression vectors were incubated in the presence of $768 \mu \mathrm{M}$ 5-FU. After isolation of total protein lysates, immunoblot analysis, using a specific antibody directed to the active p18 caspase-3 fragment, served as an indicator of apoptosis D. Probing of GAPDH was used to confirm equal loading of the samples (A-D) or as an indicator of fractionation efficacy (C). In (B), processed caspase- 8 fragments are indicated with asterisks.

Yet, among chemical inhibitors with the potential to delimit or enhance proteolytic cleavage, only zVADfmk blocked the generation of the fragment, leading to the conclusion that its appearance is a consequence of caspase activity (Figure 4F). Importantly, recombinant DR5 lacking the integral membrane domain, thus acting as a soluble inhibitor of extracellular TRAIL, failed to interfere with the cell death progression in 5-FU-treated cells, while blocking TRAIL-stimulated apoptosis completely, as shown by FACS analysis of Sub G1populations (Figure 4G), and apoptotic markers in SDSPAGE (Supplementary figure 7). In contrast, RNAi targeting of TRAIL abrogated cell death irrespectively of p53 function (Figure 4H). Hence, although mechanisms for DR4 and DR5 activation supported by intracellular, membrane bound TRAIL are lacking in the literature, our results demonstrate their existence. In conclusion, these experiments indicate 5-FU as a chemotherapeutic drug enabling apoptosis by p53-facilitated DISC oligomerization in a TRAIL-dependent manner.

\section{5-FU induces apoptosis through an RNA-stress- related pathway}

In contrast to other chemotherapeutic agents, metabolized 5-FU elicits not only damage to DNA 
but also influences RNA metabolism. Discrimination between these stress targets can be accomplished by analysis of whether thymidine or uridine reverses 5-FUinduced toxicity in cells $[9,21]$. 5-FU desensitization of cells by thymidine can be explained by enhanced dTMP production through the thymidine kinase (TK) salvage pathway, thereby reducing the requirement for TS activity. Adding an excess of uridine to the system, on the other hand, reduces RNA-misincorporation of FUTP. Our results confirm data indicating HCT116 cells as being primarily susceptible to 5-FU-induced RNA-related stress and consequently toxicity-liberated by the addition of equimolar concentrations of uridine to the system (Figure 5A) [9]. By using the same approach we also concluded that in the absence of p53 the primary 5-FU stress target point remained unaltered (Figure 5B). Uridine also inhibits 5-FU-induced LDH-release in HCT116 $p 53^{-1-}$ cells, thus validating our data concluding that slow apoptosis proceedings may result in necrotic cell features (Supplementary figure 8). Together these data clearly indicate a p53-facilitated functional link between RNA lesions and DISC-regulated apoptosis. They also support the idea of p53 as mainly functioning in the regulation of apoptotic mechanisms and not being involved in processes dictating the relative RNA/DNA-targeting of 5-FU metabolites. It is clear, however, that depending on their origin, tumor cell types respond differentially to 5-FU metabolites [21]. Intriguingly, levels of the p53 protein remain in 5-FU-uridine co-treatment (Figure 5A and 5C). Phospho-activation of p53 S15, S46 and S33, on the other hand, was reduced compared to cells treated with 5-FU alone (Figure 5C), thus verifying that uridine is acting upstream of p53.

We reasoned that if a cell line subjected to 5-FU suffers from the inhibition of TS, it is likely that imbalances of the nucleotide pool would lead to DNA
A

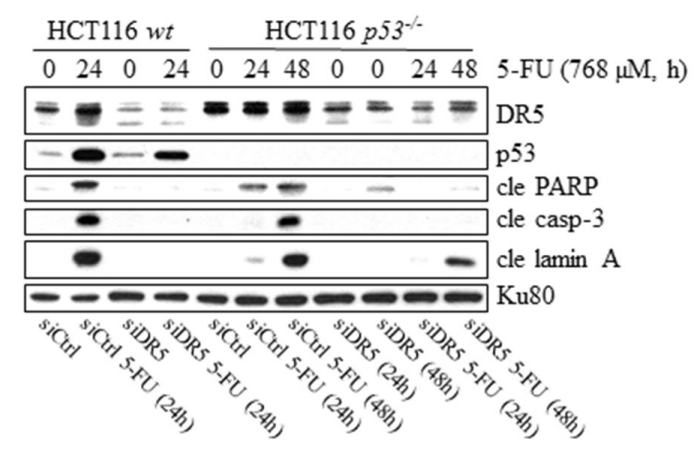

B

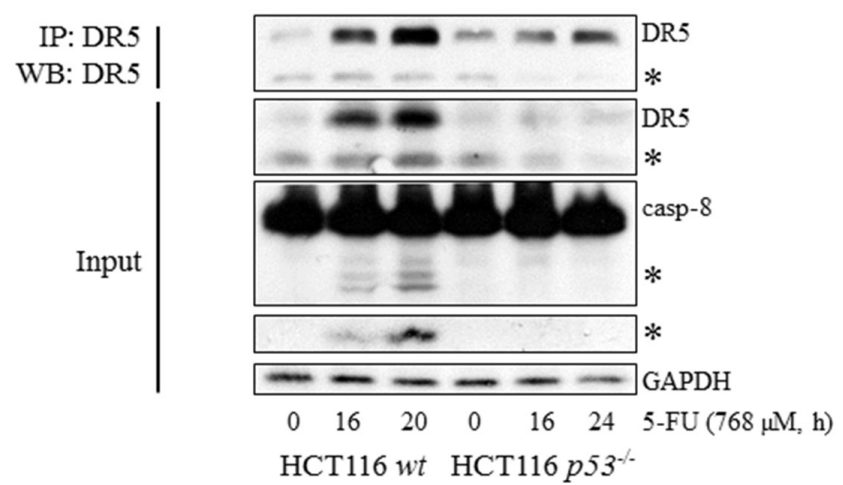

$\mathrm{C}$
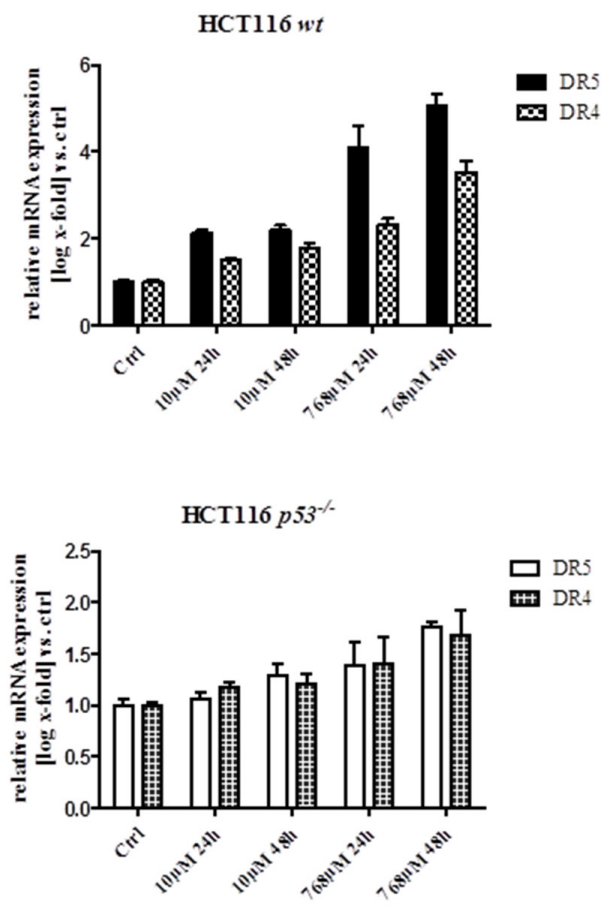

Figure 4: Independently from p53, plasma membrane accumulation of DR5 occurs in response to 5-FU treatment, and silencing of the protein reduces drug-induced apoptosis. The effect of 5-FU with respect to the processing of caspase-3, PARP and lamin A in HCT116 wt and p53 cells was analyzed by immunoblotting, using total protein lysates from cells in which DR5 had been silenced by means of RNAi (30 nmol) A. Western blot analysis of lysate input and DR5 IP generated from control and 5-FU-induced HCT116 $p 53^{-/}$and $w t$ cells. DR5 and caspase-8 processing is shown in input samples B. cDNA from control and treated (10 and $768 \mu \mathrm{M}$ 5-FU) HCT116 wt and $p 53^{-/}$cells were generated and mRNA expression analyses with respect to DR4 and DR5 were accomplished by RT-PCR using specific primers C. Along with control cells, HCT116 $p 53^{-\%}$ cells induced with 5-FU for $48 \mathrm{~h}$ were fixed in $4 \%$ formaldehyde and stained with a DR5-specific antibody (green). Cell nuclei were counterstained by DAPI (blue) and samples analyzed using confocal microscopy D. Western blot analysis of DR5-dimerization using non-reduced protein lysates isolated from control and 5-FU-treated HCT116 $w t$ and $p 53^{--}$cells. Reduced samples were separated in SDS-PAGE for detection of p53 and cle PARP E.

(Continued) 
$\mathrm{D}$
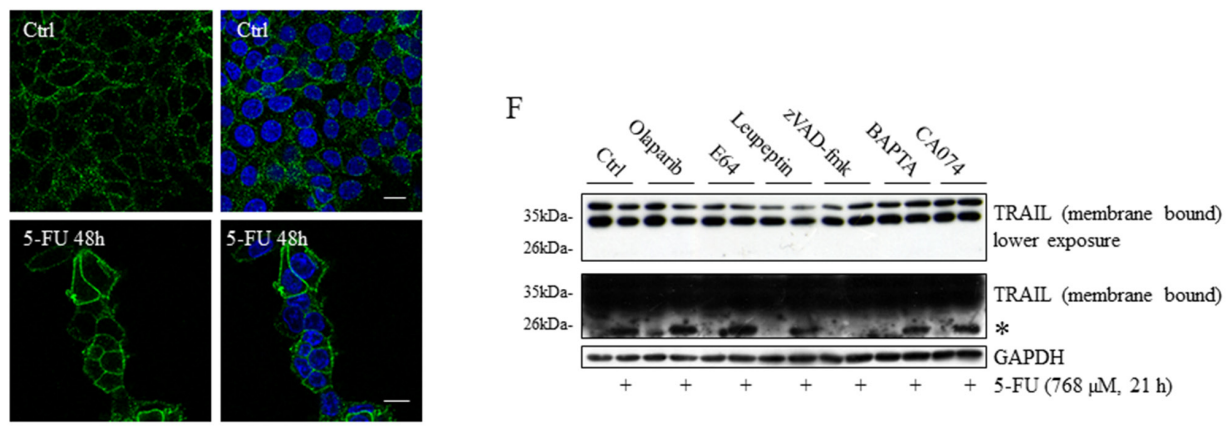

E

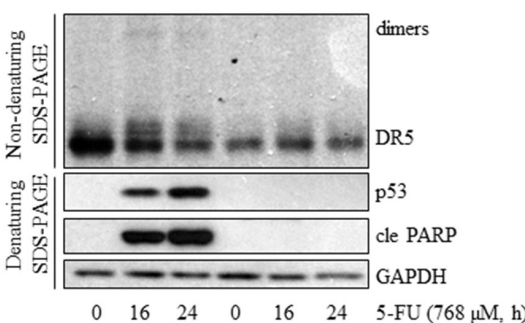

G

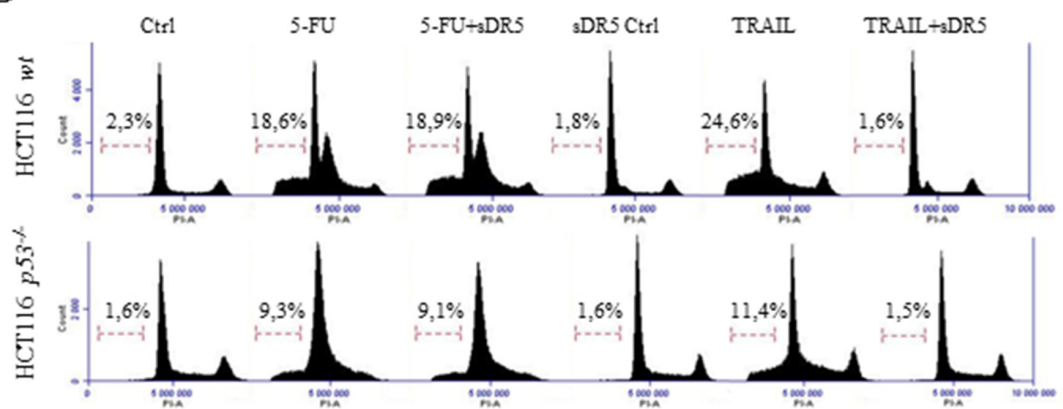

$\mathrm{H}$

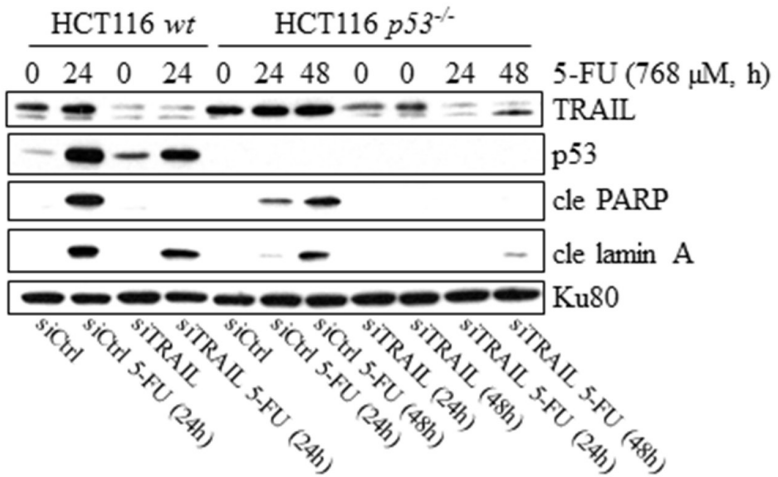

Figure 4: (Continued) Appearance of processed TRAIL was investigated by SDS-PAGE using HCT116 wt cell samples, either treated with 5-FU alone or in combination with olaparib $(500 \mathrm{nM})$, E64 $(10 \mu \mathrm{M})$, leupeptin $(100 \mu \mathrm{M})$, zVAD-fmk $(10 \mu \mathrm{M})$, BAPTA $(10 \mu \mathrm{M})$ or CA074 $(10 \mu \mathrm{M}) \mathbf{F}$. Cells, treated either with 5-FU $(30 \mu \mathrm{M}, 48 \mathrm{~h})$ or recombinant TRAIL (10 ng/ml) alone, or in combination with a soluble recombinant DR5 $(2 \mu \mathrm{g} / \mathrm{ml}$; sDR5), were fixed in ethanol and stained with propidium iodide before FACS determination of subG1 populations G. Cells were transfected with siRNA targeting TRAIL (30 nmol) $24 \mathrm{~h}$ in advance of 5-FU-treatment. Protein lysates were isolated and separated by SDS-PAGE in order to analyze TRAIL, cle lamin A and p53 using specific antibodies H. GAPDH and Ku80 were used as a control for equal loading of samples in (A, B, E, F and H). Processed TRAIL and caspase-8 as well as the short isoforms of DR5 are indicated with asterisks (B and F). Bars, $10 \mu \mathrm{m}$ (D). 
A

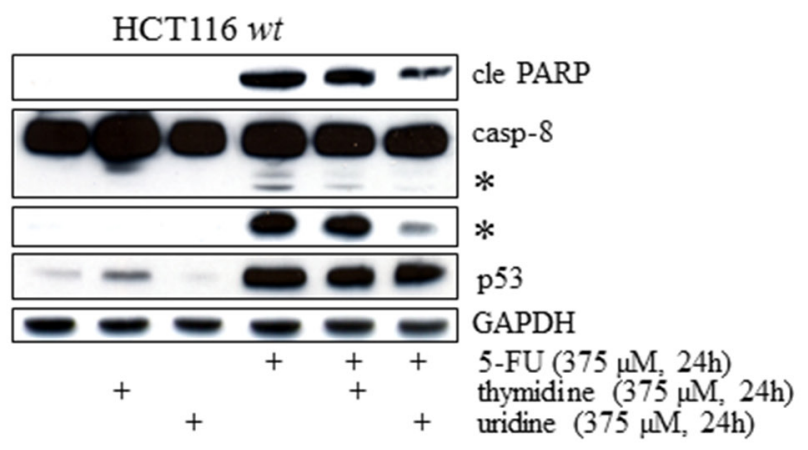

$\mathrm{C}$

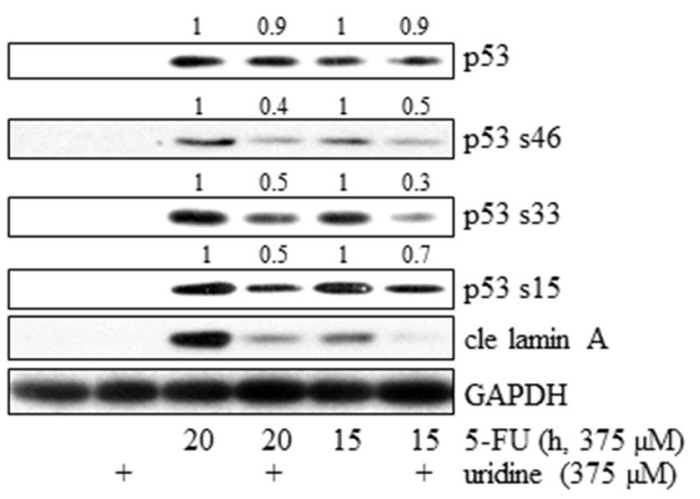

B

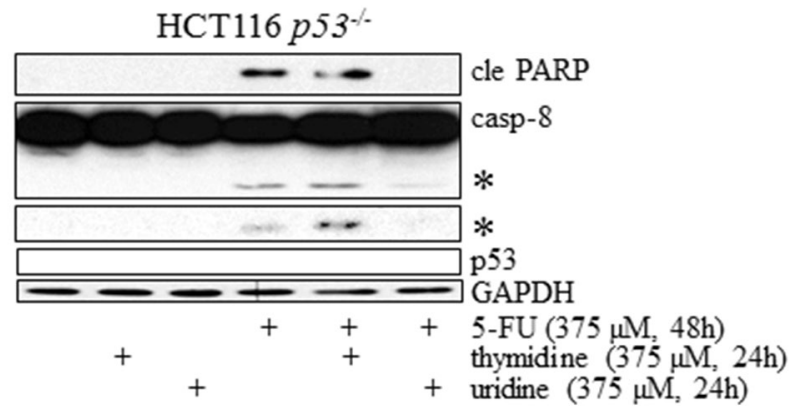

Figure 5: Irrespectively of p53 status, induction of apoptosis in HCT116 cells occurs as a consequence of 5-FU-mediated RNA-stress. HCT116 wt A. and $p 53^{--}$B. cells were treated with 5-FU alone for 24 and $48 \mathrm{~h}$, respectively, in the absence or in the presence of either thymidine or uridine. Total cell lysates were then separated by SDS-PAGE and analyzed by immunoblotting with respect to p53, caspase- 8 and cle PARP. In a similar experimental set-up, phospho-activation of p53 (S15 S33 and S46) was analyzed by SDS-PAGE in HCT116 wt cells treated with 5-FU $(375 \mu \mathrm{M})$ alone $(15$ or $20 \mathrm{~h})$ and compared to the p53 phospho-status in lysates isolated from cells co-treated with an equimolar concentration of uridine. Quantifications of p53 and its phospho-variants were accomplished through normalization with GAPDH. 15 and $20 \mathrm{~h}$ treatments are normalized separately C. Probing of GAPDH was used to confirm equal loading of the samples $(\mathrm{A}-\mathrm{C})$. Processed caspase- 8 is indicated with asterisks (A and $\mathrm{B})$.

double-strand breaks (DSB) through perturbations in the replication and repair mechanisms. Massive phosphoactivation of the histone $\mathrm{H} 2 \mathrm{AX}(\gamma \mathrm{H} 2 \mathrm{AX})$, one of the widely used markers for DSB, were indeed detected in HCT116 wt and p53-deficient cells but seem to appear simultaneously with lamin cleavage (Figure 6A and 6B). Therefore, we next investigated whether DNA damage is a cause or consequence of 5-FU-induced apoptosis. In the presence or absence of a functional p53, the addition of $\mathrm{zVAD}$-fmk in combination with 5-FU reduced $\gamma \mathrm{H} 2 \mathrm{AX}$ to background levels, demonstrating DNA damage to be a secondary event occurring as a result of apoptosis (Figure 6C). In agreement with these results, immunostaining associated $\gamma \mathrm{H} 2 \mathrm{AX}$ with cleaved lamin A and condensed nuclei in treated cells (Figure 6D). In contrast, treatment with other chemotherapeutic agents, including doxorubicin, cisplatin and camptothecin, generated $\gamma \mathrm{H} 2 \mathrm{AX}$ activity, which remained in the presence of zVAD-fmk (Figure 6C). A similar pattern was also detected in etoposide (VP16)-treated HCT116 $p 53^{-/-}$cells. However, neither the apoptotic marker cle PARP nor $\gamma \mathrm{H} 2 \mathrm{AX}$ appeared in $w t$ samples harvested $24 \mathrm{~h}$ postetoposide induction. DNA stress results in the activation of PARP-1 and PARP-2, which, among other things, catalyzes the assembly of poly(ADP-ribose) (PAR) chains onto itself and adjacent nuclear proteins, a modification that serves to facilitate repair by attracting PAR-binding DNA repair factors [22]. By using PAR polymers as a marker for DNA lesions, our conclusion that DNA damage is a secondary event to 5-FU-induced apoptosis could be verified (Figure 6C). Similar to $\gamma \mathrm{H} 2 \mathrm{AX}$, PAR remained in the presence of zVAD-fmk when cells were treated by the alternative chemotherapeutic agents. Finally, DNAdamage and apoptosis originating from 5-FU-mediated TS inhibition would theoretically be augmented by leucovorin (folinic acid), which is acting in synergy with 5-FU with respect to TS silencing. However, any enhancement of apoptosis was not detected by combinatorial treatment 
A

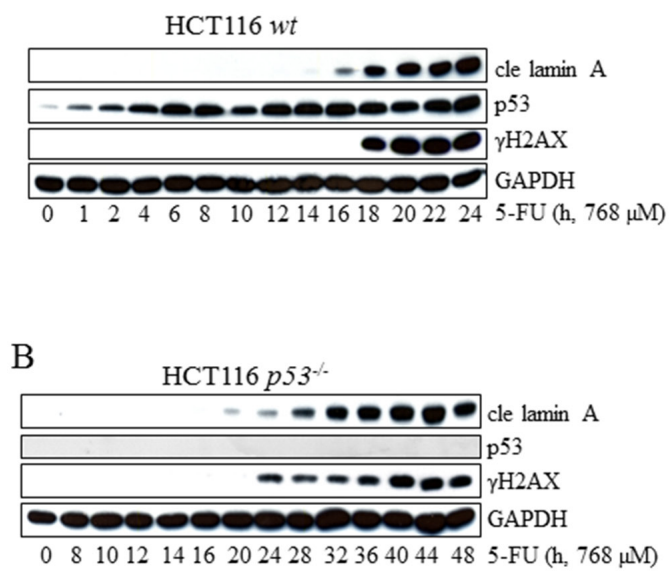

$\mathrm{C}$

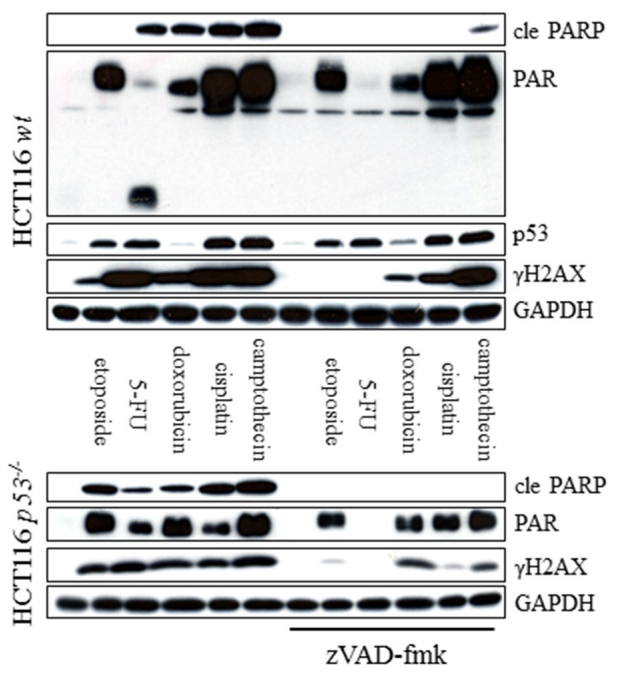

D

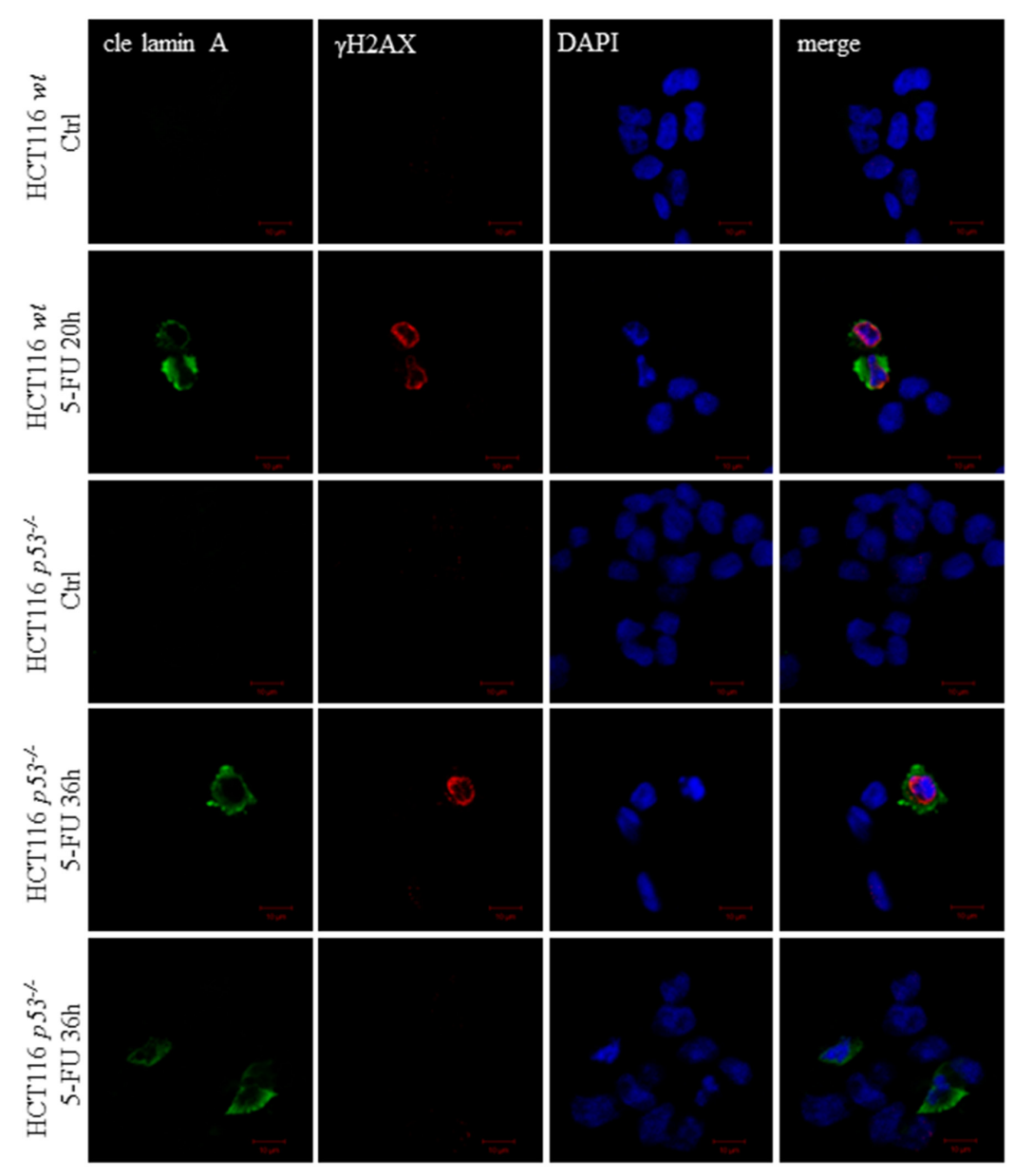

Figure 6: Markers of DNA damage appear as a consequence of 5-FU-induced caspase-activity. Analysis of p53, cle lamin A and $\gamma \mathrm{H} 2 \mathrm{AX}$ in SDS-PAGE separated protein lysates from HCT116 $w t$ A. and HCT116 $p 53^{-\sim}$ cells B. harvested at multiple time points post-5-FU-treatment. HCT116 wt and $p 53^{-}$cells were treated for 24 and $48 \mathrm{~h}$, respectively, with the chemotherapeutic agents indicated, either alone, or in the presence of $10 \mu \mathrm{M}$ zVAD-fmk. Total cell lysates were then analyzed by immunoblotting with respect to the apoptotic marker cle PARP and the DNA-damage indicators $\gamma \mathrm{H} 2 \mathrm{AX}$ and PAR C. Probing of GAPDH was used to confirm equal loading of the samples (A-C). Along with control cells, HCT116 cells ( $w t$ and $p 53^{-/}$) induced with 5-FU for 20 and $36 \mathrm{~h}$, respectively, were fixed in $4 \%$ formaldehyde immunostained using cle lamin A (green) and $\gamma \mathrm{H} 2 \mathrm{AX}$ (red) specific antibodies. Cell nuclei were counterstained by DAPI (blue) and samples analyzed by confocal microscopy D. Bars, $10 \mu \mathrm{m}$. 
using leucovorin and 5-FU compared to 5-FU alone (Supplementary figure 9). In conclusion, these results indicate that irrespectively of p53 function and in contrast to a panel of other anti-tumor agents, primary DNA damage may not be the origin of 5-FU-induced apoptosis in some cell lines.

\section{Sensitization of tumor cell lines to 5-FU by chemical- and RNAi-mediated inhibition of PARP occurs specifically in the absence of p53}

Several members of the PARP protein family, including PARP1-4 as well as tankyrase-1 and -2 have poly(ADP-ribosyl)ation activity, enabling transfer of ADP-ribose molecules to substrate proteins (PARylated proteins). This posttranslational modification is associated with several biological processes but its implication in the recognition and repair of DNA damage has so far been the main focus for future tumor therapies. In particular, inhibition of PARP-1 using small molecule inhibitors has received interest due to promising effects, both as a single agent and in combinatorial treatment regimens [23]. Although the marker for DNA DSB $\gamma \mathrm{H} 2 \mathrm{AX}$ is activated as a consequence of apoptosis in the current experimental system, studies using radiolabeled 5-FU have concluded that drug metabolites are misincorporated into DNA in a general fashion $[24,25]$. At present, no such examination has been performed using HCT116 cells, but since uridine and not thymidine reverses 5-FUinduced apoptosis, any toxicity evolving from DNA stress might be suppressed by a shielding DNA repair capacity, resulting in cell death as a consequence of other stress targets such as RNA. Accordingly, manipulation of DNA repair systems could be a feasible approach to enhance the apoptotic 5-FU response in some tumor cells [26]. As PARP-1 has been implicated in several modes of single- and double-strand DNA repair, including base excision repair (BER), homologous recombination (HR) and non-homologous end joining (NHEJ) [23], we examined the combinatorial treatment effects of 5-FU and olaparib (PARP1-4 inhibitor) [27]. To our surprise, in comparison to 5-FU alone, an enhancement of cleaved caspase- 3 and the processing of caspase- 8 were detected by SDS-PAGE specifically in HCT116 $p 53^{-\sim}$ cells. Moreover, $\gamma \mathrm{H} 2 \mathrm{AX}$ signals also remained after the addition of zVAD-fmk to combinatory-treated cells, indicating primary DNA damage only in the absence of p53 (Figure 7A). With respect to apoptosis, a similar response pattern, using lamin A cleavage as an indicator of apoptosis and sub G1-populations of overall cell death, was confirmed by RNAi-targeting of PARP1, thereby identifying this particular member of the protein family as the main contributor of the effect (Figure 7B and 7C). Even if olaparib and siRNA contributed to 5-FUinduced apoptosis in HCT116 $p 53^{-/}$cells, the overall response was still low compared to the wt counterpart treated with 5-FU as a single agent (Figure 7A-7C). However, using extended incubation times with lower 5-FU concentrations, we clearly demonstrated that the apoptotic ratio between p53-deficient cells treated with the olaparib combinatorial setting and 5-FU alone not only persisted but actually increased significantly, while it remained constant in p53 wt cells (Supplementary figure 10). In addition, to verify the general validity of our data, p53 was suppressed by siRNA in RKO cells, which were subsequently treated with either 5-FU or olaparib alone, or their combination. Similar to what was concluded in HCT116 cells, a synergetic effect of the drugs was detected only in RKO cells transfected with p53 siRNA (Figure 7D). Although a more detailed mechanistic explanation for this finding remains to be established, the data may certainly be of importance for the design of future combinatorial tumor therapies.

\section{DISCUSSION}

The metabolic activation of 5-FU potentiates several distinct stress conditions within cancer cells. As TK misrecognizes FdUMP as a substrate, its enzymatic silencing renders dTTP starvation and elevated dUTP pools, which in turn lead to nucleotide misincorporation and mutagenesis, as well as to defects in DNA replication and repair processes. In addition, several lines of evidences support a model where drug toxicity is generated from RNA-related effects. While early works associated tumor cell lethality with the incorporation of 5-FU into RNA [28, 29], recent achievements have further specified mechanisms leading to malfunctioning rRNA processing and pre-mRNA splicing defects as explanations for drug-induced toxicity [30, 31]. Although experimental evidences are lacking, the fast post-transcriptional reduction of ribosomal proteins and translational capacity in treated cells might reflect early rRNA processing disorders [32]. Apart from apoptosis, stress conditions resulting from 5-FU treatment include the unfolded protein response (UPR) succeeding endoplasmic reticulum (ER) stress and stimulation of autophagy [33, 34]. To our knowledge, a more complete view of how these response patterns interrelate has not yet been presented. Interestingly, however, as a way to maintain cell homeostasis, ER stress may reduce translational capacity via the inhibition of rRNA synthesis and stimulation of autophagy [35], processes which are associated with 5-FU treatment.

Our aim was to establish a functional connection leading from a specific drug target point to a discrete cell death mechanism and further describe how p53-deficiency interferes with this process (Figure 8). Obtained data supports the notion that apoptotic mechanisms induced by 5-FU originate from RNA-related stress, at least in selected cell types. In view of the fact that uridine but not thymidine liberates cells from apoptotic stress stimulated 
by 5-FU-metabolites in a p53-independent manner, the tumor suppressor status of cells may not be an answer to why different cell lines seem to differ with respect to drug stress origin. Results from the functional assay using free nucleosides were confirmed by the disclosure of $\gamma \mathrm{H} 2 \mathrm{AX}$ and PAR-appearances as secondary to apoptotic initiation. Phospho-activation of $\mathrm{H} 2 \mathrm{AX}$ occurring as a consequence of apoptosis has been investigated in some detail by others. In line with our findings, it has been reported that DISCmediated apoptosis may stimulate not only $\gamma \mathrm{H} 2 \mathrm{AX}$ but also other factors associated with the DNA damage response [36]. The expression pattern and the activating kinase were shown to diverge between apoptosis- and DNA damagestimulated phosphorylation of histone H2AX. Importantly,

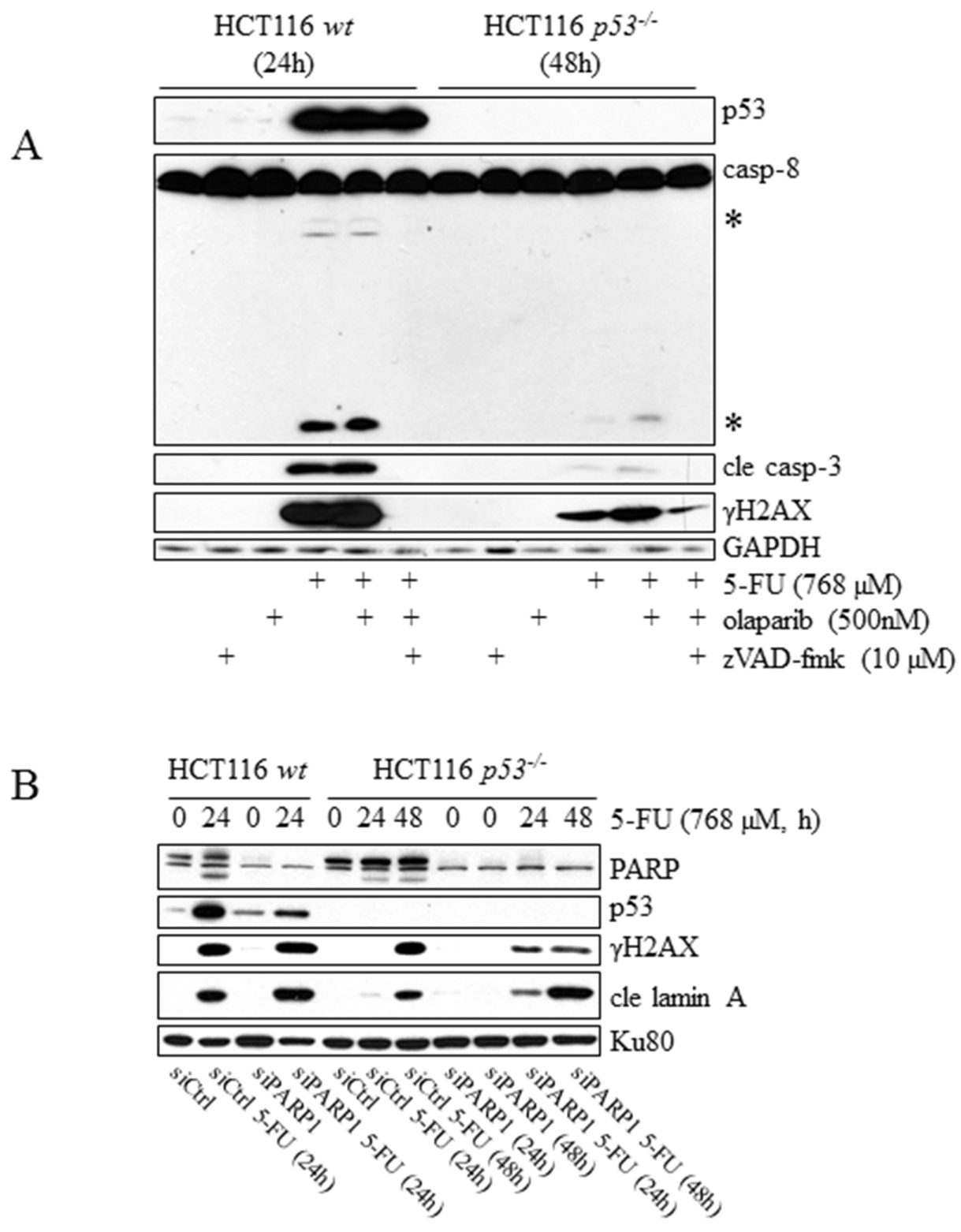

Figure 7: Sensitization of tumor cell lines to 5-FU by chemical and RNAi-mediated inhibition of PARP occurs specifically in the absence of p53. HCT116 $w t$ and $p 53^{--}$cells, incubated in the presence of 5-FU alone for 24 and $48 \mathrm{~h}$, respectively, or co-treated with $500 \mathrm{nM}$ of the PARP inhibitor olaparib. Total cell lysates were then analyzed by immunoblotting with respect to p53, processing of caspases- 8 and -3 , and $\gamma \mathrm{H} 2 \mathrm{AX} \mathbf{A}$. The effect of 5-FU-treatment with respect to $\mathrm{p} 53$ and the processing of lamin A in HCT116 $w t$ and $p 53^{-}$cells was analyzed by immunoblotting using total protein lysates from cells in which PARP1 had been silenced by means of RNAi $(30 \mathrm{nmol})$. A non-targeting control siRNA was used to eliminate the possibility that transfections per se interfered with analysis outcome B. The consequence of 5-FU treatment with respect to sub G1 populations in HCT116 wt and $p 53^{-/}$cells was analyzed by FACS using cells in which PARP 1 had been silenced by means of RNAi (30 nmol) C.

(Continued) 

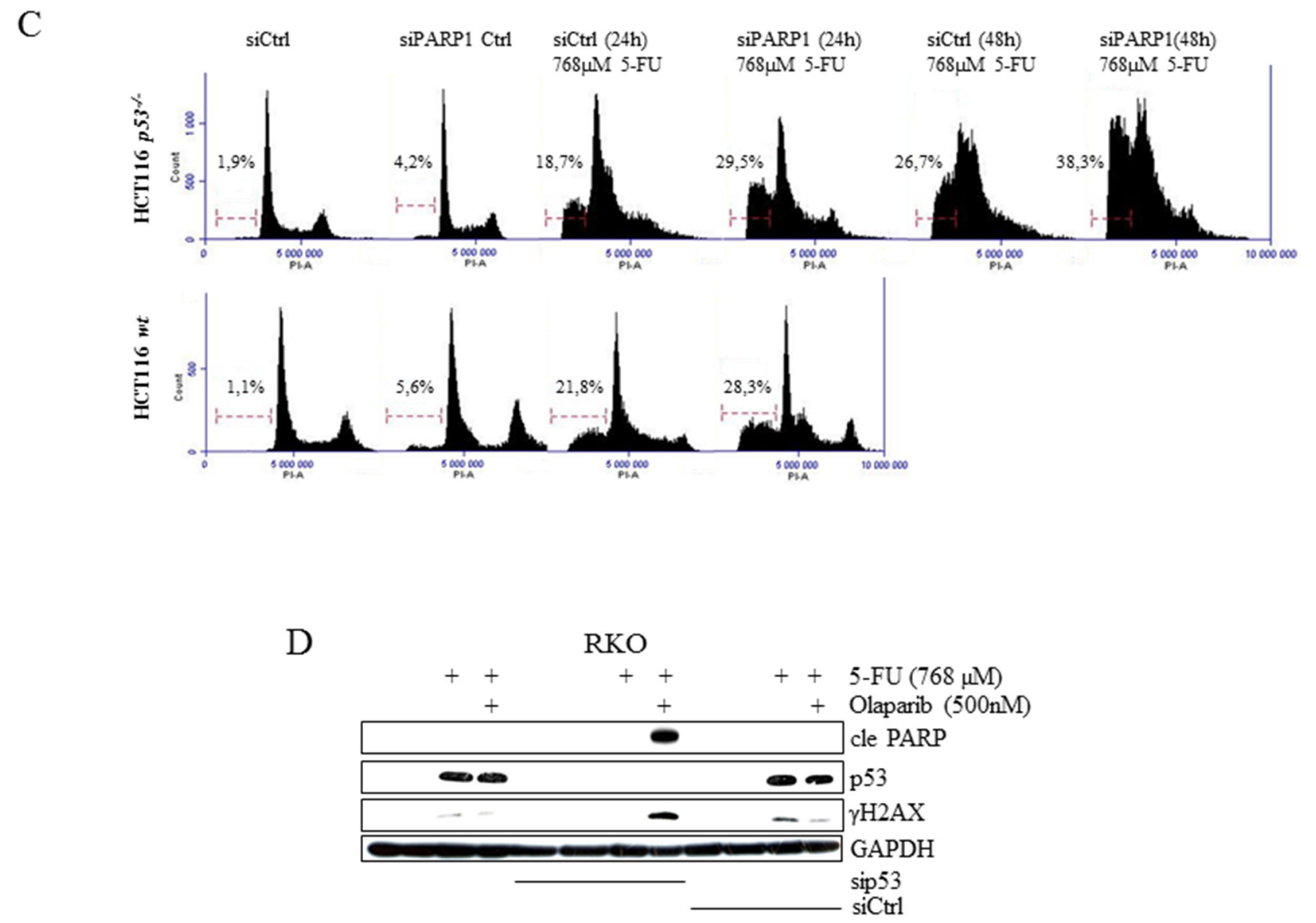

Figure 7: (Continued) Immunoblot-detection of DNA-damaging ( $\gamma \mathrm{H} 2 \mathrm{AX})$ and apoptotic (cle PARP) markers in 5-FU-treated RKO control cells, and in cells where p53 suppression was accomplished by means of RNAi. Comparisons of control, si control (sictrl) and sip53 transfected cells are outlined in D. GAPDH and Ku80 were used as a control for equal loading of samples (A, B and D). Processed caspase- 8 is indicated with asterisks (A).

in contrast to apoptotic caspase-dependent Chk2-activity, $\gamma \mathrm{H} 2 \mathrm{AX}$ did not amplify the proceedings of cell death [36, 37], which is in line with our previous observations [6]. Instead, apoptotic H2AX activity seems to be important for nuclear morphological changes, and especially caspaseactivated DNase (CAD)-mediated DNA-ladder formation [37]. To what extent PAR also participates in any such processes is currently not known. In contrast to 5-FUtreated cells, where both PAR and $\gamma \mathrm{H} 2 \mathrm{AX}$ were reduced below detection level in the presence of a pan-caspaseinhibitor, signals decreased but remained measurable in experimental conditions embracing co-treatment with alternative chemotherapeutic agents. Apart from serving as positive controls for primary DNA damage, diminished $\gamma \mathrm{H} 2 \mathrm{AX}$ in these samples also indicate that apoptosis- and DNA-damage-stimulated phosphorylation of the histone may occur simultaneously in cells. PAR, on the other hand, persisted when zVAD-fmk was combined with all drugs except 5-FU, thus implying caspase-dependent PAR formation as being specific to this particular treatment regimen. The significance of the DISC for 5-FU-induced apoptosis was accomplished by no less than five discrete approaches: FLIP $_{\mathrm{L}}$ and FADD-DN overexpression, as well as RNAi-targeting of DR4, DR5 and caspase-8. Combined with the fact that uridine hindered caspase- 8 processing and that zVAD-fmk reduced markers of DNA damage to background levels, the current data set is indicating a link between 5-FU-induced RNA-stress and the apoptotic initiating point constituted by DR4 and DR5 (Figure 8). How, then, is death receptors oligomerized? The conclusion from our data set is that the cognate receptor ligand TRAIL is obligatory for DISC aggregation and initiation of the caspase cascade. However, activation of DR4 and DR5 seems to occur via intracellular, membrane bound TRAIL. Thereby, TRAIL, DR4 and DR5 are specified as rate-limiting factors for 5-FU-induced toxicity, and in agreement with previous reports, p53 contributes to transcriptional regulation of the corresponding genes $[18,38]$. Delimitation of either factor may consequently be the explanation for why suboptimal apoptosis occurs in cells lacking the tumor suppressor. Since preclinical models demonstrated that recombinant TRAIL has 


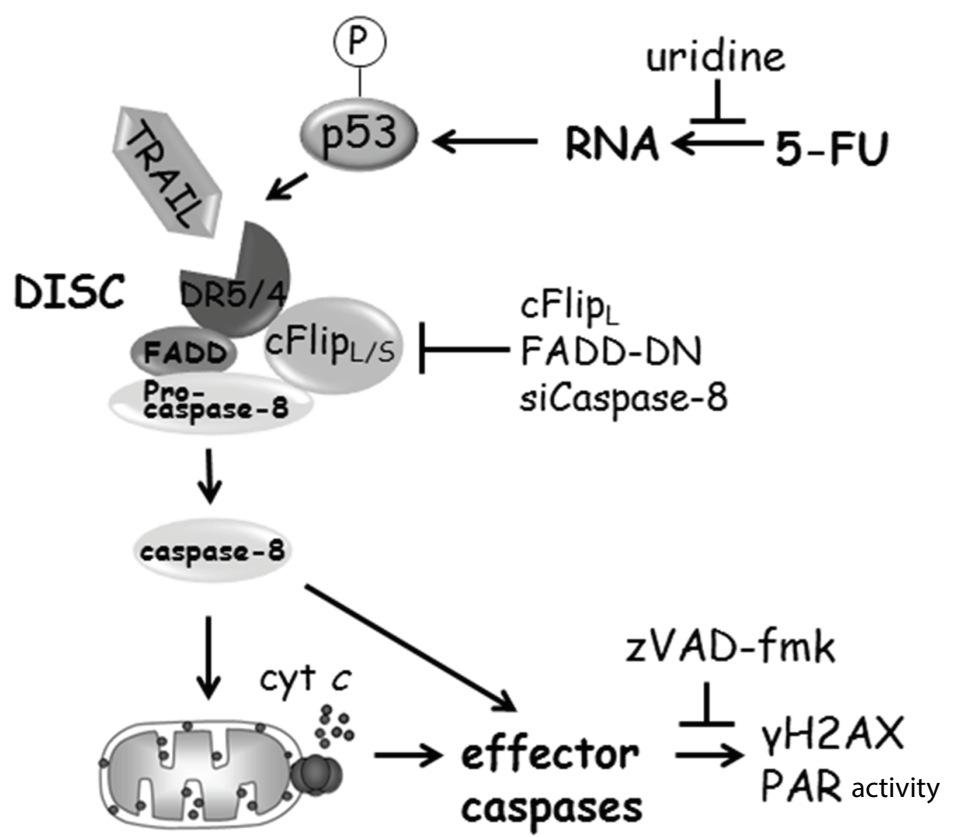

Figure 8: Schematic illustration of 5-FU-induced apoptotic signaling in HCT116 cells (for details, see text).

potent anti-tumor activity without exhibiting systemic cytotoxicity [39], DR4 and DR5 were postulated as potential targets for future cancer therapeutics. In fact, agents with pronounced anti-tumorigenic potential, such as inhibitors of histone deacetylases (HDACIs), retinoids and interferons, depend on TRAIL expression and the subsequent activation of death receptors for the execution of tumor cell death $[18,38]$. The conclusion from the present work is that 5-FU may also stimulate a similar death process. It must be noted that details regarding the TRAIL-DR4/5-interaction requires further exploration. In silico analysis of TRAIL using an algorithm for the prediction of transmembrane helices and their orientation (TMHMM; Center for Biological Sequence Analysis, Technical University of Denmark) indicated the ligand as a mainly cytosolic type 1 integral membrane protein. Accordingly, soluble TRAIL (sTRAIL) is generated within cells and then exported for subsequent receptor oligomerization. A processed TRAIL variant was indeed detected in treated samples by SDS-PAGE, but loss of the band in 5-FU and zVAD-fmk co-treated cells suggests that the appearance of this potential sTRAIL occurs as a consequence of caspase activity. Since reduced but still significant induction of $D R 4$ and $D R 5$ gene transcription could also be detected in the absence of p53, it is clear that transcription factors separated from the $\mathrm{p} 53$ protein network support gene expression. For 5-FU-induced apoptosis, these factors remain elusive but zerumbone and celecoxib, two ER stress-inducing drugs, were recently shown to activate DR5 transcription by means of the activating transcription factor 4 (ATF4)/C/EBP homologous protein and $\mathrm{CHOP} / \mathrm{ATF} 3$ transcriptional cascade in a p53-independent manner [19]. Whether p53transcriptional regulation of Bax or PUMA also contributes to the efficiency of 5-FU-induced apoptosis has not been investigated. However, considering their central role in the deregulation of mitochondrial membrane potential, it is likely. Our data verify a signaling link between RNArelated stress and DISC-mediated apoptosis. Although RNA lesions seem to serve as a foundation for caspase cascade initiation, we cannot exclude the possibility that silent genomic stress is introduced by 5 -FU metabolites, for example through FdUTP misincorporation. In fact, data revealing specific augmentation of caspase activation by olaparib and 5-FU co-treatment in p53-deficient cells is in support of such a scenario. Since PARP-1 has been implicated in the BER process, stalled enzyme efficiency induced by RNAi or chemical inhibitors may lead to a more prominent damaging effect of 5-FU on DNA [23]. Present data only allows us to speculate regarding the reasons why PARP-1 inhibition or RNAi silencing in combination with 5-FU primarily affects p53-negative HCT116 cells. One explanation could be synthetic lethality, where the absence of p53 renders cells with additional DNA repair defects and thus greater sensitivity to combined treatment with PARP-inhibitors and 5-FU. For example, it was shown that HR deficiency caused by phosphatase and tensin homolog (PTEN) mutations sensitizes tumor cells to PARP inhibitors, both in vitro and in vivo [40]. Similarly, selective anti-proliferative effects of BRCA1 or BRCA2 (breast cancer, early onset)deficient tumors have been demonstrated with olaparib [41]. Alternatively, p53 has also been reported to stimulate BER directly [42], thus suggesting those cells lacking 
the tumor suppressor to be more susceptible to PARP inhibition. In conclusion, our results show that 5-FU can stimulate TRAIL- and DR4/5-dependent apoptosis, which is facilitated by p53 but still proceeds in the absence of the tumor suppressor. Although the dominant origin for the process seems to be RNA-related, further analyses should be designed to elucidate whether or not other stress targets of the drug also contribute to the chemotherapeutic response.

\section{MATERIALS AND METHODS}

\section{Cell culture}

The HCT116 parental cell line, its variants (kindly provided by Professor Bert Vogelstein) and RKO cells (ATCC) were cultured in Dulbecco's modified Eagle's medium (DMEM), supplemented with heat-inactivated FBS (10\%) (GIBCO, Invitrogen, San Diego, CA, USA) and PenStrep (100 U/ml penicillin, $100 \mathrm{mg} / \mathrm{ml}$ streptomycin; Sigma-Aldrich, Saint Luis, MO, USA). Cell-treatment with the antimetabolite 5-FU (Accord Healthcare Ltd, Harrow, UK) was performed at concentrations and incubationtimes as indicated in the figures. In selected experiments the synthetic pan-caspase inhibitor N-benzyloxycarbonylVal-Ala-Asp(O-Me) fluoromethyl ketone (zVAD-fmk, $10 \mu \mathrm{M})$ (Peptide Institute, Inc., Osaka, Japan), the PARP inhibitor olaparib (500 nM; Selleck Chemicals, Houston, TX, USA), E64D (10 $\mu \mathrm{M}$; Sigma-Aldrich), pepstatin A (7 $\mu \mathrm{M}$; Sigma-Aldrich), leupeptin $(100 \mu \mathrm{M}$; Sigma-Aldrich), BAPTA (10 $\mu \mathrm{M}$; Life Technologies, Carlsbad, CA, USA), recombinant soluble DR5 $(2 \mu \mathrm{g} / \mathrm{ml}$; Sigma-Aldrich), recombinant TRAIL $(10 \mathrm{ng} / \mathrm{ml}$; Life Technologies), leucovorin (Hospira Nordic AB, Stockholm, Sweden) or CA074 (10 $\mu \mathrm{M}$; Sigma-Aldrich) were added to cell cultures $1 \mathrm{~h}$ prior to drug treatment. In addition, treatments of cells using doxorubicin $(2 \mu \mathrm{M}$; Sigma-Aldrich), uridine (375 $\mu \mathrm{M}$; Sigma-Aldrich), thymidine (375 $\mu \mathrm{M}$; Sigma-Aldrich), etoposide (20 $\mu \mathrm{M}$; Ebewe, Austria), cisplatin (40 $\mu \mathrm{M}$; Ebewe, Austria) and camptothecin (600 nM; Sigma-Aldrich) were performed in selected experiments.

\section{Mitochondrial AIF and cytochrome c release}

Detection of mitochondrial AIF and cytochrome $c$ release was accomplished by the digitonin (Calbiochem, San Diego, CA USA) organelle fractionation procedure performed as described [43].

\section{Analysis of mitochondrial membrane potential and ROS}

Mitochondrial membrane potential $\left(\Delta \Psi_{\mathrm{m}}\right)$ was estimated with TMRE (tetra-methyl-rhodamine-ethyl ester, Life Technologies). Cells were incubated for $20 \mathrm{~min}$ in Hank's balanced salt solution (Life Technologies) containing $0.1 \mu \mathrm{M}$ TMRE. For assessment of mitochondrial ROS, cells were stained with MitoSOX ${ }^{\mathrm{TM}}$ Red (Life Technologies) according to the manufacturer's recommendations. Analyses were accomplished by using a FACScan Becton Dickinson flow cytometer using the accompanying software.

\section{Gel electrophoresis and immunoblotting}

SDS-PAGE was performed according to previously described procedures [6].

\section{DR5 dimerization assay}

DR5 dimers were analyzed by SDS-PAGE using lysates isolated without reducing agent. Cells were treated with 5-FU, washed with PBS, and lysed for $20 \mathrm{~min}$ on ice in $20 \mathrm{mM}$ Tris- $\mathrm{HCl}$ (pH 7.5), $150 \mathrm{mM} \mathrm{NaCl}, 10 \%$ glycerol, and $1 \%$ Triton X-100 supplemented with cOmplete phosphatase/protease inhibitors (Roche Diagnostics). After centrifuged at $16,000 \times \mathrm{g}$ at $4^{\circ} \mathrm{C}$, the cleared lysates were divided into two aliquots and diluted with $3 \times$ SDS sample buffer with or without $\beta$-mercaptoethanol. The samples containing reducing agent were incubated at $95^{\circ} \mathrm{C}$ for $5 \mathrm{~min}$, whereas the non-reduced samples were kept at RT before loading.

\section{Expression vectors and retroviral transduction}

The retroviral expression vectors pLXINhFADD and $\mathrm{pXINhFLIP}_{\mathrm{L}}$ have been described previously [44]. Retroviral particles were produced by transient transfection of the Phoenix-Ampho packaging cell line (kindly provided by Dr. GP Nolan, Stanford University, USA). Production of viral particles and retroviral transductions were performed as described [44]. Transduced cells were selected by treatment with $0.8 \mathrm{mg} /$ $\mathrm{ml}$ of Geneticin (Invitrogen).

\section{RNA isolation and RT-PCR}

Total RNA was isolated from control and 5-FUtreated HCT116 wt and $p 53^{--}$cells with RNAeasy mini kit (Qiagen) according to the manufacturer's instructions. The Maxima First Strand cDNA Synthesis Kit was used for cDNA synthesis (Life Technologies). Gene expression was measured using Maxima SYBR Green qPCR Master Mix (Fermentas) with Applied Biosystems 7500 Real-time PCR (Applied Biosystems). Relative gene expression was calculated with $2^{-\Delta \Delta} \mathrm{Ct}$ method using Actin expression for normalization.

\section{Primers used}

DR5 (F-TCAGGTGAAGTGGAGCTAAGTC, R-GTGTACAATCACCGACCTT), 


\section{DR4 (F-ACTCGCTGTCCACTTTCGTCTCTGA, R-AGGCATCCCCTGGGCCTGCTGTA), actin (F-GCTGTGCTATCCCTGTACGC, R-GAGGGCATACCCCTCGTAGA).}

\section{Transmission electron microscopy}

Cells were fixed in $2.5 \%(\mathrm{w} / \mathrm{v})$ glutaraldehyde in $0.1 \mathrm{M}$ phosphate buffer, $\mathrm{pH} 7.4$ for $30 \mathrm{~min}$ at RT, and fixed in the same fixative in the refrigerator. After rinsing in $0.1 \mathrm{M}$ phosphate buffer cells were centrifuged and the pellets post fixed in $2 \%(\mathrm{w} / \mathrm{v})$ osmium tetroxide in $0.1 \mathrm{M}$ phosphate buffer ( $\mathrm{pH} 7.4$ ) at $4^{\circ} \mathrm{C}$ for $2 \mathrm{~h}$, dehydrated in ethanol followed by acetone, and embedded in LX-112 (Ladd). Ultrathin sections ( 40-50 nm) were cut using a Leica EM UC 6 ultramicrotome. Sections were subsequently contrasted with uranyl acetate followed by lead citrate and examined in a Tecnai 12 Spirit Bio TWIN transmission electron microscope (FEI) at $100 \mathrm{kV}$. Digital images were taken using a Veleta camera (Olympus Soft Imaging Solutions).

\section{Immunofluorescence}

Immunocytochemistry was performed according to previously described procedures [6].

\section{Antibodies}

The following primary antibodies were used in western blotting: anti-p53 monoclonal antibody, antiAIF (Santa Cruz Biotechnology, Santa Cruz, CA, USA), anti-PAR mAb, anti-GAPDH polyclonal antibody (pAb; Trevigen, Gaithersburg, MD, USA), anti-phospho-p53 pAbs (Ser 15, 33, and 46), anti-cleaved-caspase-3 pAb, anti- $\gamma \mathrm{H} 2 \mathrm{AX}$ (Ser 139) pAb; cleaved PARP mAb (Asp214), cleaved lamin A mAb, PERK mAb (Cell Signaling, Danvers, MA, USA), anti-tubulin mAb, anti-DR5 pAb; anti-DR4 pAb (Sigma-Aldrich), anti-PARP mAb, anti-cytochrome $c$, anti-TRAIL mAb, Ku80 mAb (BD Biosciences, Franklin Lakes, NJ, USA), anti-cFLIP mAb (Alexis, San Diego, $\mathrm{CA}, \mathrm{USA}$ ) and anti-caspase- $8 \mathrm{mAb}$ (kindly provided by Professor PH Krammer and Dr. I Lavrik, German Cancer Research Center, Heidelberg, Germany). Analysis of DR5 in immunofluorescence was performed using the mAb F2/ B4 (kindly provided by Dr. L Andêra, Academy of Sciences, Prague, Czech Republic). For other immunofluorescence stainings, antibodies identical to those in western blotting procedures were used. Fluorescent secondary antibodies directed against mouse and rabbit (Alexa488 and Alexa594) were purchased from Molecular Probes (Invitrogen).

\section{Measurement of caspase-3/-7-like activities}

Measurement of the caspase-3/-7-like substrate Ac-DEVD-AMC (acetyl Asp-Glu-Val-Asp 7-amido4-methylcoumarin; Peptide Institute, Osaka, Japan) cleavage was performed as described [45].

\section{RNA interference}

Transfection of TRAIL (siTNFSF10, s16665), DR5 (siTNFSF10B, s16756), DR4 (siTNFSF10A, s16764), negative control (siNegative Control No1) (silencer select, Life Technologies), p53 (siTP53-9,FlexiTube), PARP (siPARP1 HP Custom siRNA Qiagen, Hilden, Germany), caspase-8 (L-003466-00) and negative control (D-00120613) ONTARGET-plus SMARTpool siRNAs (Dharmacon, CO, Lafayette, USA) was performed using the Lipofectamine RNAiMAX transfection reagent (Life Technologies) according to the manufacturer's instructions.

\section{Colony assay}

Eighteen cells per $\mathrm{cm}^{2}$ were seeded one day in advance of experimental onset. 5-FU at concentrations indicated in the figures was maintained for $48 \mathrm{~h}$. Cell colonies were then allowed to form over 10 days before staining in a $0.04 \%(\mathrm{w} / \mathrm{v})$ crystal violet solution.

\section{Lactate dehydrogenase (LDH) measurement}

Analysis of homogeneous plasma membrane integrity was used as an indicator of necrosis by taking advantage of the fluorometric CytoTox-ONE ${ }^{\mathrm{TM}}$ Assay (Promega, Madison, WI, USA) and by following the manufacturer's recommendations.

\section{Cell cycle and sub G1 analysis}

Harvested cells were fixed in $70 \%$ ethanol for $1 \mathrm{~h}$ at $4^{\circ} \mathrm{C}$. Repeated washes in PBS and RNase A ( $100 \mu \mathrm{g} / \mathrm{ml}$, Invitrogen) treatment for $1 \mathrm{~h}$ at $37^{\circ} \mathrm{C}$ were followed by propidium iodide staining $(50 \mu \mathrm{g} / \mathrm{ml}$, Sigma-Aldrich). Analysis in FL3 on DDM mode was performed using the BD Accuri C6 system in combination with BD CSampler software (Becton-Dickinson, San Jose, CA, USA).

\section{Immunoprecipitation of DR5}

Immunoprecipitation of DR5 was performed using the protocol described and taking advantage of the specific DR5 mAb (clone F2/B4, $3 \mu \mathrm{g} / \mathrm{ml}$ IP buffer) [43].

\section{Statistical analysis}

Results are expressed as the mean \pm standard deviation (SD). GraphPad Prism 5.02 software and $t$-test were used in analysis.

\section{ACKNOWLEDGMENTS}

We thank Professors Bert Vogelstein, Peter H. Krammer, Inna N. Lavrik, and Dr. Ladislav Anděra for their contribution of cells and antibodies. We would also 
like to mark our gratitude to Dr. Kjell Hultenby for his assistance in TEM. This study was supported by grants from the Swedish Science Foundation, the Swedish and Stockholm Cancer Societies, the Swedish Childhood Cancer Foundation the Czech Science Foundation (project No. 15-06650S) and European Regional Development Fund (CZ.1.07/2.3.00/20.0180). MO is a fellow of the Swedish Society of Medical Research.

\section{CONFLICTS OF INTEREST}

The authors declare no conflict of interest.

\section{REFERENCES}

1. Longley DB, Harkin DP, Johnston PG. 5-fluorouracil: mechanisms of action and clinical strategies. Nat Rev Cancer. 2003; 3:330-338.

2. Scherf U, Ross DT, Waltham M, Smith LH, Lee JK, Tanabe L, Kohn KW, Reinhold WC, Myers TG, Andrews DT, Scudiero DA, Eisen MB, Sausville EA, Pommier Y, Botstein D, Brown PO, et al. A gene expression database for the molecular pharmacology of cancer. Nat Genet. 2000; 24:236-244.

3. Noordhuis P, Holwerda U, Van der Wilt CL, Van Groeningen CJ, Smid K, Meijer S, Pinedo HM, Peters GJ. 5-Fluorouracil incorporation into RNA and DNA in relation to thymidylate synthase inhibition of human colorectal cancers. Ann Oncol. 2004; 15:1025-1032.

4. Xiao Z, Xue J, Sowin TJ, Rosenberg SH, Zhang H. A novel mechanism of checkpoint abrogation conferred by Chk1 downregulation. Oncogene. 2005; 24:1403-1411.

5. Hwang PM, Bunz F, Yu J, Rago C, Chan TA, Murphy MP, Kelso GF, Smith RA, Kinzler KW, Vogelstein B. Ferredoxin reductase affects p53-dependent, 5-fluorouracilinduced apoptosis in colorectal cancer cells. Nat Med. 2001; 7:1111-1117.

6. Can G, Akpinar B, Baran Y, Zhivotovsky B, Olsson M. 5-Fluorouracil signaling through a calcium-calmodulindependent pathway is required for $\mathrm{p} 53$ activation and apoptosis in colon carcinoma cells. Oncogene. 2013; 32:4529-4538.

7. Wang S, El-Deiry WS. Inducible silencing of KILLER/DR5 in vivo promotes bioluminescent colon tumor xenograft growth and confers resistance to chemotherapeutic agent 5-fluorouracil. Cancer Res. 2004; 64:6666-6672.

8. O'Connor PM, Jackman J, Bae I, Myers TG, Fan S, Mutoh M, Scudiero DA, Monks A, Sausville EA, Weinstein JN, Friend S, Fornace AJ Jr., Kohn KW. Characterization of the p53 tumor suppressor pathway in cell lines of the National Cancer Institute anticancer drug screen and correlations with the growth-inhibitory potency of 123 anticancer agents. Cancer Res. 1997; 57:4285-4300.

9. Bunz F, Hwang PM, Torrance C, Waldman T, Zhang Y, Dillehay L, Williams J, Lengauer C, Kinzler KW, Vogelstein B. Disruption of p53 in human cancer cells alters the responses to therapeutic agents. J Clin Invest. 1999; 104:263-269.

10. Lowe SW, Bodis S, McClatchey A, Remington L, Ruley HE, Fisher DE, Housman DE, Jacks T. p53 status and the efficacy of cancer therapy in vivo. Science. 1994; 266:807-810.

11. Elsaleh H, Powell B, Soontrapornchai P, Joseph D, Goria F, Spry N, Iacopetta B. p53 gene mutation, microsatellite instability and adjuvant chemotherapy: impact on survival of 388 patients with Dukes' C colon carcinoma. Oncology. 2000; 58:52-59.

12. Yang B, Eshleman JR, Berger NA, Markowitz SD. Wildtype p53 protein potentiates cytotoxicity of therapeutic agents in human colon cancer cells. Clin Cancer Res. 1996; 2:1649-1657.

13. Ozoren N, Kim K, Burns TF, Dicker DT, Moscioni AD, El-Deiry WS. The caspase 9 inhibitor Z-LEHD-FMK protects human liver cells while permitting death of cancer cells exposed to tumor necrosis factor-related apoptosisinducing ligand. Cancer Res. 2000; 60:6259-6265.

14. Artus C, Boujrad H, Bouharrour A, Brunelle MN, Hoos S, Yuste VJ, Lenormand P, Rousselle JC, Namane A, England P, Lorenzo HK, Susin SA. AIF promotes chromatinolysis and caspase-independent programmed necrosis by interacting with histone H2AX. EMBO J. 2010; 29:1585-1599.

15. Vaculova A, Kaminskyy V, Jalalvand E, Surova O, Zhivotovsky B. Doxorubicin and etoposide sensitize small cell lung carcinoma cells expressing caspase-8 to TRAIL. Mol Cancer. 2010; 9:87.

16. Duiker EW, de Vries EG, Mahalingam D, Meersma GJ, Boersma-van Ek W, Hollema H, Lub-de Hooge MN, van Dam GM, Cool RH, Quax WJ, Samali A, van der Zee AG, de Jong S. Enhanced antitumor efficacy of a DR5-specific TRAIL variant over recombinant human TRAIL in a bioluminescent ovarian cancer xenograft model. Clin Cancer Res. 2009; 15:2048-2057.

17. Liu X, Yue P, Khuri FR, Sun SY. p53 upregulates death receptor 4 expression through an intronic $\mathrm{p} 53$ binding site. Cancer Res. 2004; 64:5078-5083.

18. Wu GS, Burns TF, McDonald ER, 3rd, Jiang W, Meng R, Krantz ID, Kao G, Gan DD, Zhou JY, Muschel R, Hamilton SR, Spinner NB, Markowitz S, Wu G, el-Deiry WS. KILLER/DR5 is a DNA damageinducible p53-regulated death receptor gene. Nat Genet. 1997; 17:141-143.

19. Edagawa M, Kawauchi J, Hirata M, Goshima H, Inoue M, Okamoto T, Murakami A, Maehara Y, Kitajima S. Role of Activating Transcription Factor 3 (ATF3) in Endoplasmic Reticulum (ER) Stress-induced Sensitization of p53deficient Human Colon Cancer Cells to Tumor Necrosis Factor (TNF)-related Apoptosis-inducing Ligand (TRAIL)mediated Apoptosis through Up-regulation of Death Receptor 5 (DR5) by Zerumbone and Celecoxib. J Biol Chem. 2014; 289:21544-21561. 
20. Mariani SM, Krammer PH. Differential regulation of TRAIL and CD95 ligand in transformed cells of the T and B lymphocyte lineage. Eur J Immunol. 1998; 28:973-982.

21. Petak I, Tillman DM, Houghton JA. p53 dependence of Fas induction and acute apoptosis in response to 5 -fluorouracil-leucovorin in human colon carcinoma cell lines. Clin Cancer Res. 2000; 6:4432-4441.

22. El-Khamisy SF, Masutani M, Suzuki H, Caldecott KW. A requirement for PARP-1 for the assembly or stability of XRCC1 nuclear foci at sites of oxidative DNA damage. Nucleic Acids Res. 2003; 31:5526-5533.

23. Wang Z, Wang F, Tang T, Guo C. The role of PARP1 in the DNA damage response and its application in tumor therapy. Front Med. 2012; 6:156-164.

24. Sawyer RC, Stolfi RL, Martin DS, Spiegelman S. Incorporation of 5-fluorouracil into murine bone marrow DNA in vivo. Cancer Res. 1984; 44:1847-1851.

25. Major PP, Egan E, Herrick D, Kufe DW. 5-Fluorouracil incorporation in DNA of human breast carcinoma cells. Cancer Res. 1982; 42:3005-3009.

26. Wyatt MD, Wilson DM. 3rd. Participation of DNA repair in the response to 5-fluorouracil. Cell Mol Life Sci. 2009; 66:788-799.

27. Wahlberg E, Karlberg T, Kouznetsova E, Markova N, Macchiarulo A, Thorsell AG, Pol E, Frostell A, Ekblad T, Oncu D, Kull B, Robertson GM, Pellicciari R, Schuler H, Weigelt J. Family-wide chemical profiling and structural analysis of PARP and tankyrase inhibitors. Nat Biotechnol. 2012; 30:283-288.

28. Kufe DW, Major PP. 5-Fluorouracil incorporation into human breast carcinoma RNA correlates with cytotoxicity. J Biol Chem. 1981; 256:9802-9805.

29. Glazer RI, Lloyd LS. Association of cell lethality with incorporation of 5-fluorouracil and 5-fluorouridine into nuclear RNA in human colon carcinoma cells in culture. Mol Pharmacol. 1982; 21:468-473.

30. Fang F, Hoskins J, Butler JS. 5-fluorouracil enhances exosome-dependent accumulation of polyadenylated rRNAs. Mol Cell Biol. 2004; 24:10766-10776.

31. Zhao X, Yu YT. Incorporation of 5-fluorouracil into U2 snRNA blocks pseudouridylation and pre-mRNA splicing in vivo. Nucleic Acids Res. 2007; 35:550-558.

32. Marin-Vicente C, Lyutvinskiy Y, Romans Fuertes P, Zubarev RA, Visa N. The effects of 5-Fluorouracil on the proteome of colon cancer cells. J Proteome Res. 2013; 12:1969-1979.

33. Yadunandam AK, Yoon JS, Seong YA, Oh CW, Kim GD. Prospective impact of 5-FU in the induction of endoplasmic reticulum stress, modulation of GRP78 expression and autophagy in Sk-Hep1 cells. Int J Oncol. 2012; 41:1036-1042.
34. Pan X, Zhang X, Sun H, Zhang J, Yan M, Zhang H. Autophagy inhibition promotes 5-fluorouraci-induced apoptosis by stimulating ROS formation in human non-small cell lung cancer A549 cells. PLoS One. 2013; 8:e56679.

35. Verfaillie T, Salazar M, Velasco G, Agostinis P. Linking ER Stress to Autophagy: Potential Implications for Cancer Therapy. Int J Cell Biol. 2010; 2010:930509.

36. Solier S, Sordet O, Kohn KW, Pommier Y. Death receptor-induced activation of the Chk2- and histone H2AX-associated DNA damage response pathways. Mol Cell Biol. 2009; 29:68-82.

37. Lu C, Zhu F, Cho YY, Tang F, Zykova T, Ma WY, Bode AM, Dong Z. Cell apoptosis: requirement of H2AX in DNA ladder formation, but not for the activation of caspase-3. Mol Cell. 2006; 23:121-132.

38. Kuribayashi K, Krigsfeld G, Wang W, Xu J, Mayes PA, Dicker DT, Wu GS, El-Deiry WS. TNFSF10 (TRAIL), a p53 target gene that mediates p53-dependent cell death. Cancer Biol Ther. 2008; 7:2034-2038.

39. Johnstone RW, Frew AJ, Smyth MJ. The TRAIL apoptotic pathway in cancer onset, progression and therapy. Nat Rev Cancer. 2008; 8:782-798.

40. Mendes-Pereira AM, Martin SA, Brough R, McCarthy A, Taylor JR, Kim JS, Waldman T, Lord CJ, Ashworth A. Synthetic lethal targeting of PTEN mutant cells with PARP inhibitors. EMBO Mol Med. 2009; 1:315-322.

41. Bryant HE, Schultz N, Thomas HD, Parker KM, Flower D, Lopez E, Kyle S, Meuth M, Curtin NJ, Helleday T. Specific killing of BRCA2-deficient tumours with inhibitors of poly(ADP-ribose) polymerase. Nature. 2005; 434:913-917.

42. Song S, Xing G, Yuan L, Wang J, Wang S, Yin Y, Tian C, He F, Zhang L. N-methylpurine DNA glycosylase inhibits p53-mediated cell cycle arrest and coordinates with p53 to determine sensitivity to alkylating agents. Cell Res. 2012; 22:1285-1303.

43. Olsson M, Vakifahmetoglu H, Abruzzo PM, Hogstrand K, Grandien A, Zhivotovsky B. DISC-mediated activation of caspase-2 in DNA damage-induced apoptosis. Oncogene. 2009; 28:1949-1959.

44. Djerbi M, Darreh-Shori T, Zhivotovsky B, Grien A. Characterization of the human FLICE-inhibitory protein locus and comparison of the anti-apoptotic activity of four different flip isoforms. Scandinavian journal of immunology. 2001; 54:180-189.

45. Vakifahmetoglu H, Olsson M, Orrenius S, Zhivotovsky B. Functional connection between p53 and caspase- 2 is essential for apoptosis induced by DNA damage. Oncogene. 2006; 25:5683-5692. 